\title{
Transient plasma injections in the dayside magnetosphere: one-to-one correlated observations by Cluster and SuperDARN
}

\author{
A. Marchaudon ${ }^{1}$, J.-C. Cerisier ${ }^{1}$, J.-M. Bosqued ${ }^{2}$, M. W. Dunlop ${ }^{3,}$, J. A. Wild ${ }^{4}$, P. M. E. Décréau ${ }^{5}$, M. Förster ${ }^{6}$, \\ D. Fontaine ${ }^{7}$, and H. Laakso ${ }^{8}$ \\ ${ }^{1}$ Centre d'Etude des Environnements Terrestre et Planétaires, 4 avenue de Neptune, 94107 Saint-Maur-des-Fossés Cedex, \\ France \\ ${ }^{2}$ Centre d'Etude Spatiale des Rayonnements, CESR/CNRS, B.P. 4346, 31028 Toulouse Cedex 4, France \\ ${ }^{3}$ Space and Atmospheric Physics, Blackett Laboratory, Imperial College, London SW7 2BZ, UK \\ ${ }^{4}$ Department of Physics and Astronomy, University of Leicester, University Road, Leicester, LE1 7RH, UK \\ ${ }^{5}$ LPCE and Université d'Orléans, 45071 Orléans, France \\ ${ }^{6}$ Max Planck-Institute für Extraterrestrische Physik, 85741 Garching, Germany \\ ${ }^{7}$ Centre d'Etude des Environnements Terrestre et Planétaires, 10-12 avenue de 1'Europe, 78140 Vélizy, France \\ ${ }^{8}$ Space Science Division, ESTEC, Noordwijk, The Netherlands \\ *now at: RAL, Rutherford-Appleton Laboratory, Chilton, Didcot, Oxon, OX11 0QX, UK
}

Received: 11 December 2002 - Revised: 2 June 2003 - Accepted: 9 June 2003 - Published: 1 January 2004

\begin{abstract}
Conjunctions in the cusp between the four Cluster spacecraft and SuperDARN ground-based radars offer unique opportunities to compare the signatures of transient plasma injections simultaneously in the high-altitude dayside magnetosphere and in the ionosphere. We report here on such observations on 17 March 2001, when the IMF initially northward and duskward, turns southward and dawnward for a short period. The changes in the convection direction at Cluster are well correlated with the interplanetary magnetic field (IMF) $B_{y}$ variations. Moreover, the changes in the ionosphere follow those in the magnetosphere, with a 2-3 min delay. When mapped into the ionosphere, the convection velocity at Cluster is about 1.5 times larger than measured by SuperDARN.

In the high-altitude cusp, field and particle observations by Cluster display the characteristic signatures of plasma injections into the magnetosphere suggestive of Flux Transfer Events (FTEs). Simultaneous impulsive and localized convection plasma flows are observed in the ionospheric cusp by the HF radars. A clear one-to-one correlation is observed for three successive injections, with a 2-3 min delay between the magnetospheric and ionospheric observations. For each event, the drift velocity of reconnected flux tubes (phase velocity) has been compared in the magnetosphere and in the ionosphere. The drift velocity measured at Cluster is of the order of $400-600 \mathrm{~m} \mathrm{~s}^{-1}$ when mapped into the ionosphere, in qualitative agreement with SuperDARN observations. Finally, the reconnected flux tubes are elongated in the northsouth direction, with an east-west dimension of $30-60 \mathrm{~km}$ in the ionosphere from mapped Cluster observations, which is
\end{abstract}

Correspondence to: A. Marchaudon

(aurelie.marchaudon@cetp.ipsl.fr) consistent with SuperDARN observations, although slightly smaller.

Key words. Ionosphere (plasma convection) - Magnetospheric physics (magnetopause, cusp, and boundary layers; magnetosphere-ionosphere interactions)

\section{Introduction}

Plasma entry from the solar wind into the magnetosphere occurs mainly through the dayside magnetopause. Three main regions just inside the magnetopause with different plasma characteristics, have been recognized since the initial survey by Heos-2 (Haerendel et al., 1978): the low-latitude boundary layer (LLBL), the high-altitude cusp and the plasma mantle. Across these boundary regions, a competition exists between diffusion and reconnection for mass, momentum and energy transfer from the solar wind to the magnetosphere. The low-latitude magnetopause adjacent to the LLBL is the main site for reconnection (Eastman et al., 1976; Newell and Meng, 1988; Fuselier et al., 1999), when the interplanetary magnetic field (IMF) is southward. The LLBL is populated by a mixture of plasmas of magnetosheath and magnetospheric origin and is partly located on closed field lines. The LLBL is magnetically connected to the ionospheric cleft (Newell and Meng, 1988), where particle fluxes are lower in intensity and extend to higher energies than in the cusp located just poleward (Aparicio et al., 1991). The highaltitude cusp (Paschmann et al., 1976) is located on open field lines, where magnetosheath plasma entry is more direct, as indicated by the spectral characteristics of the particles which are close to those observed in the magnetosheath (Newell and 
Meng, 1988). The high-altitude cusp is magnetically connected to the "cusp proper" at lower altitudes, where plasma with magnetosheath characteristics is also observed. The persistency of the cusp proper has led many authors (e.g. Newell et al., 1989) to conclude that processes other than patchy or transient merging occur in the high-altitude cusp such as steady-state merging or diffusion. Poleward of the high-altitude cusp, is the plasma mantle (Rosenbauer et al., 1975; Crooker et al., 1977). This boundary layer consists of magnetosheath-like plasma with a tailward-directed bulk flow parallel to the local magnetic field. Particles entering the cusp may move on mantle field lines through convection and are dispersed by the velocity filter effect (Reiff et al., 1977). For strongly northward IMF, the high-latitude magnetopause adjacent to the mantle is the preferred site of reconnection (Maezawa, 1976).

Reconnected magnetic flux tubes allow energy and momentum transfer from the solar wind to the magnetosphere. Initially considered as a steady-state process, its intermittent and spatially limited nature was discovered, independently by Haerendel (1978) and by Russell and Elphic $(1978,1979)$. Russell and Elphic (1978) named these bursts of magnetic reconnection, the Flux Transfer Events (FTEs) and first recognised their main observational characteristic, the bipolar signature in the magnetic field component normal to the magnetopause. Later studies allowed one to refine the description of FTEs, namely the plasma signature inside the reconnected flux tube, consisting of a mixture of magnetosheath and magnetospheric plasma (e.g. Farrugia et al., 1988), the accelerated ion flows (e.g. Paschmann et al., 1982) and their larger occurrence rate during periods of southward interplanetary magnetic field (e.g. Berchem and Russell, 1984; Lockwood and Smith, 1992).

Flux transfer events map into the ionosphere along magnetic field lines. The first observation of the ionospheric signature of an FTE was made by Goertz et al. (1985) with the STARE VHF coherent radar. Sporadic and spatially limited flow bursts moving in the northwest direction were attributed to magnetic merging, as indicated by the simultaneous observation of a satellite signature at the magnetopause. Several studies with the PACE HF radar followed, and Pinnock et al. $(1991,1993,1995)$ presented cases of enhanced convection channels superimposed on the continuous cusp echoes. Inside flow channels, the velocity was larger than in the ambient plasma and directed mainly northward, as expected by the Southwood (1987) model for FTEs. Most of these convection channels are also characterized by an azimuthal velocity component, the sign of which depends upon the sign of the IMF $B_{y}$ component. It was observed that in the Northern Hemisphere, the flow is westward for positive $B_{y}$ and eastward for negative $B_{y}$ and reversed in the Southern Hemisphere, in agreement with the convection models (Reiff and Burch, 1985; Crooker, 1979, 1988; Cowley et al., 1991), which assume that the convection is driven by the magnetic tension at the reconnection site. It was also observed that the longitudinal extent of these flow bursts is generally larger than their latitudinal extent and that their average repetition rate is about $7 \mathrm{~min}$. Parallel currents flowing on the flanks of the flow burst have been modelled (Southwood, 1987; Lockwood et al., 1990, 2001a) and observed (Milan et al., 2000). All the above observations and models suggested that intermittent and patchy magnetic reconnection was the source of FTEs, including sporadic flow bursts which represent their ionospheric signature. Observations by SuperDARN radars have complemented this set of observations. For example, Provan et al. (1998), with a high resolution scan mode, and Milan et al. (2000) and Thorolfsson et al. (2000), with the association of radars and optical observations, determined the size, shape, velocity and recurrence rate of the ionospheric signatures of FTEs. These case studies have been confirmed by statistical studies of the location, occurrence and relation with the IMF $B_{y}$ of the flow bursts (Provan and Yeoman, 1999; Provan et al., 1999; McWilliams et al., 2000).

Thus, flux transfer events (FTEs) have been extensively studied during the last twenty years, both in the magnetosphere by satellites and in the ionosphere by radars or imagers. However, simultaneous observations in the highaltitude magnetosphere and in the ionosphere are less numerous. Elphic et al. (1990) showed a clear association between an FTE, identified near the magnetopause by its magnetic bipolar signature observed by the ISEE2 satellite, and poleward-moving ionospheric flow bursts and auroral forms observed by the EISCAT radar and photometers. Almost ten years later, Neudegg et al. (1999) have associated the signatures of an FTE observed at the magnetopause by the Equator-S satellite and in the ionosphere by a SuperDARN radar. In a statistical study, Neudegg et al. (2000) showed a clear one-to-one association between reconnected flux tubes at the magnetopause and ionospheric poleward moving flow bursts.

The four-spacecraft Cluster mission, with an optimised inter-satellite separation, is well-suited to analyze the detailed structure of FTEs in the magnetosphere (Bosqued et al., 2001; Owen et al., 2001). Coordinated studies between Cluster and magnetically conjugate ground-based instruments are of primary importance to characterize the electrodynamic coupling between the ionosphere and the distant magnetosphere (Opgenoorth et al., 2001; Lockwood et al., 2001b). Clear FTE signatures have been recently observed simultaneously by ground-based instruments and Cluster (Lockwood et al., 2001c; Wild et al., 2001), illustrating the ionosphere-magnetosphere coupling caused by the magnetopause reconnection.

On 17 March 2001, between 05:05 and 06:50 UT, Cluster crosses the high-altitude northern cusp while the SuperDARN CUTLASS radars measure line-of-sight (1-o-s) velocities typical of cusp echoes in the conjugate ionosphere. The interplanetary conditions are very quiet, with a mainly northward and duskward IMF and a low solar wind pressure. The study presented in this paper is limited to a short interval between 05:15 and 06:00 UT, characterised by a southward and dawnward excursion of the IMF, leading to an increased rate of magnetic reconnection at the magnetopause. During that time period, characteristic FTE signatures are ob- 
served by Cluster in the magnetosphere, and duskward flow bursts are simultaneously observed by the CUTLASS radars in the ionosphere, at the magnetic footprint of Cluster. Cluster and radar observations are well correlated. A detailed comparison for three successive injections shows that the local plasma convection velocity and the drift velocity of the flux tubes, evaluated in the ionosphere and at 7-8 $R_{E}$ altitude (and then mapped into ionosphere) are fully consistent.

\section{Instrumentation}

\subsection{Cluster}

The Cluster mission is composed of four identical spacecraft in a tetrahedral formation in order to discriminate between small-scale spatial and temporal structures. Cluster is located on an elliptical orbit with a perigee of $4 R_{E}$, an apogee of $19.6 R_{E}$ and a period of $\sim 58 \mathrm{~h}$. In this paper, we use data from several experiments: the Cluster Ion Spectrometer (CIS), the Fluxgate Magnetometer (FGM), the Plasma Electron and Current Experiment (PEACE), the Waves of High frequency and Sounder for Probing of Electron density by Relaxation instrument (WHISPER), the Electric Field and Wave experiment (EFW) and the Electron Drift Instrument (EDI).

The Cluster Ion Spectrometry (CIS) experiment (Rème et al., 2001) provides a full, three-dimensional energy/velocity distribution of the major magnetospheric ions from thermal energies up to about $40 \mathrm{keV} / \mathrm{e}$ and the moments with a time resolution up to $4 \mathrm{~s}$. The experiment is composed of two different instruments: the COmposition and DIstribution Function analyser (CIS1/CODIF), which gives the mass per charge composition with a medium angular resolution $\left(22.5^{\circ}\right)$, and the Hot Ion Analyser (CIS2/HIA), which offers a better energy and angular resolution without mass resolution. In this study, we use energy spectrograms and the moment data (ion velocity components and density) provided by the CIS1/CODIF and CIS2/HIA instruments on Cluster 1.

In support of CIS observations, data from four other instruments have been used in this paper. The PEACE instrument (Johnstone et al., 1997) is designed to measure the electron velocity distribution. The WHISPER instrument (Décréau et al., 2001) yields the electron density determined via the passive mode of the relaxation sounder. The EFW instrument (Gustafsson et al., 2001) measures the electric field and the spacecraft potential, of which the variations are, to a large extent, proportional to those of the plasma density. The EDI instrument (Paschmann et al., 2001) measures the drift velocity of artificially injected electron beams, from which the perpendicular electric field can be deduced.

The magnetic field data are provided by the Fluxgate Magnetometer (FGM) experiment (Balogh et al., 2001). Each FGM instrument is composed of two tri-axial fluxgate magnetic field sensors. In this study, the magnetic field data are used with a resolution of $\sim 0.125 \mathrm{~s}$. By identifying similar but time-lagged signatures of boundaries on each of the four spacecraft, the FGM data are used to derive the velocity of these boundaries.

\subsection{SuperDARN}

The ionospheric convection is measured by the CUTLASS SuperDARN coherent HF radars at Hankasalmi (Finland) and Pikkvibær (Iceland) (Greenwald et al., 1995). Each radar measures the 1-o-s plasma velocity in the F-region of the ionosphere. As the CUTLASS radars share a common fieldof-view, convection velocity vectors can be obtained from the simultaneous measurement of two independent components. The SuperDARN radar beam is narrow, typically $3.3^{\circ}$ in azimuthal width, and scans successively 16 adjacent directions divided into 75 range bins of $45 \mathrm{~km}$ length. The field-of-view of each radar is large: over $3000 \mathrm{~km}$ in range and $53^{\circ}$ in azimuth. During the period under study, the two radars were operated in the high-resolution common mode, with each beam sounded for $3 \mathrm{~s}$, resulting in a full scan every $1 \mathrm{~min}$.

\section{Geometry of observations and interplanetary condi- tions}

On 17 March 2001, the magnetic footprint of the Cluster spacecraft crosses the field-of-view of the CUTLASS radars between 04:50 and 09:20 UT. During the shorter interval 05:05-06:50 UT, the Cluster spacecraft (with an average separation of $\sim 600 \mathrm{~km}$ ) encounters the northern external cusp. Cluster is moving sunward from the northern lobe through the cusp towards the dayside magnetopause close to the noon magnetic plane, as shown in Fig. 1, which represents a sketch of the projection of Cluster in the $X Z$ GSM plane. The overall cusp crossing has been analysed by Vontrat-Reberac et al. (2003). In the present paper, we focus on a short period between 05:15 and 06:00 UT, during which Cluster and SuperDARN observe in the cusp the response to a southward and dawnward excursion of the IMF. During this period, the radars are located in the pre-noon sector and observe cusp echoes in the ionosphere at very far horizontal ranges between 2700 and $3300 \mathrm{~km}$. Figure 2 shows a map of the field-of-view of the CUTLASS radars at 05:30 UT, in Altitude-Adjusted Corrected GeoMagnetic coordinates (AACGM) (Baker and Wing, 1989). The mapped ionospheric footprint of Cluster (black dot) is calculated by projection along magnetic field lines, with the Tsyganenko T96 model (Tsyganenko, 1995) and real inputs of IMF and solar wind pressure from the ACE satellite. During the period of interest, the Cluster footprint remains almost fixed and is located near $79^{\circ}$ Magnetic Latitude (MLAT) and $165^{\circ} \mathrm{Mag}$ netic Longitude (MLON), corresponding to $\sim 11: 30$ Magnetic Local Time (MLT), where cusp echoes are observed by the Hankasalmi radar.

The IMF and solar wind data are provided by the ACE satellite located near the Lagrangian L1 libration point, at about $226 R_{E}$ upstream of the Earth. The IMF data are plot- 


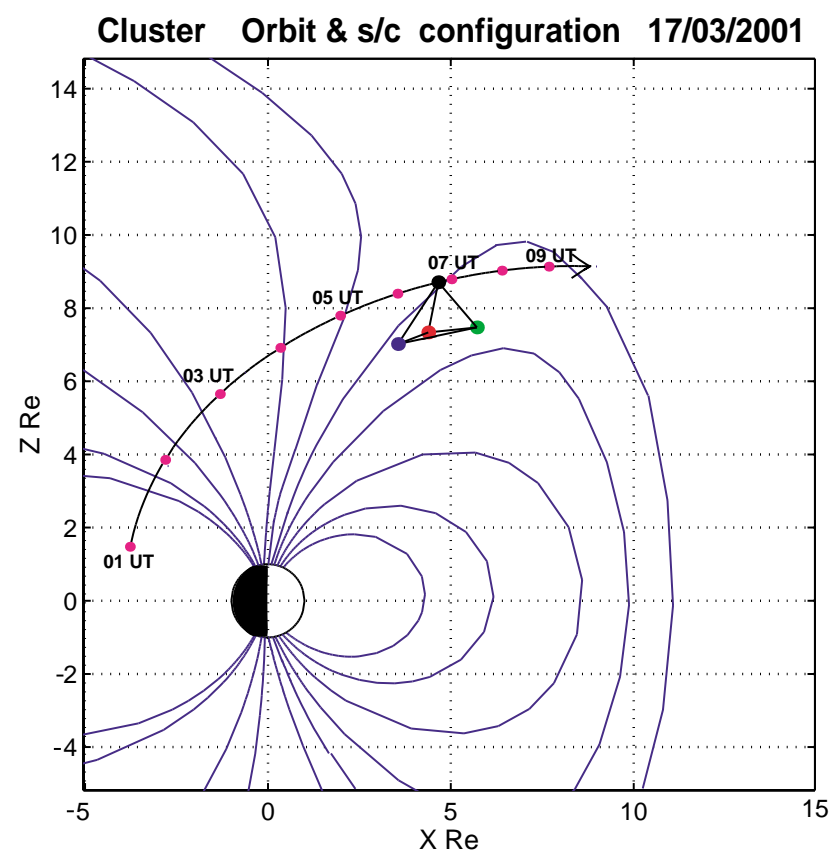

Fig. 1. Sketch of the projection of the Cluster 1 orbit (black solid line) in the GSM $X Z$ plane, for the period 01:00-09:00 UT on 17 March 2001. Magenta dots along the orbit are separated by one hour. The Cluster spacecraft configuration is shown around 06:45 UT, each spacecraft corresponding to a coloured dot with the Cluster colour-code (SC1-black, SC2-red, SC3-green, SC4-blue). The separation of the spacecraft has been expanded by a factor of ten to better indicate the tetrahedral configuration in the cusp. Several magnetospheric field lines (blue solid lines) have also been plotted.

ted in GSM coordinates with an 86-min delay in Fig. 3. The propagation delay to the dayside ionosphere is evaluated between 86 and $91 \mathrm{~min}$, taking into account a 78-min delay between the ACE and the bowshock (with a solar wind bulk speed of $\sim 290 \mathrm{~km} \mathrm{~s}^{-1}$ ), a 5- to 10-min delay across the magnetosheath (Spreiter and Stahara, 1980) and a 3-min delay between the magnetopause and the dayside ionosphere (Etemadi et al., 1988). During the interval 05:05-06:50 UT when Cluster is in the cusp, the solar wind pressure is low, less than $0.5 \mathrm{nPa}$ (not shown), and the IMF is characterised by mainly positive $B_{y}$ and $B_{z}$, both with a mean value of $+3 \mathrm{nT}$ (Fig. $3 \mathrm{~b}$ and c). The $B_{x}$ component also remains slightly positive, oscillating between 0 and $+3 \mathrm{nT}$ (Fig. 3a). But during the interval under study (05:15-06:00 UT), a rotation of the IMF is observed. Initially duskward and northward, the IMF progressively turns dawnward and then southward to reach $B_{z} \sim-2 \mathrm{nT}$ and $B_{y} \sim-5 \mathrm{nT}$ between 05:30 and 05:45 UT, after which the IMF returns to its initial direction. As $B_{z}$ remains smaller than $B_{y}$, the convection pattern is mainly controlled by the $B_{y}$ component. The rotation of the IMF is evidenced by the clock angle (Fig. 3d) which reaches a maximum of $110^{\circ}$ at $\sim 05: 40$ UT. Following Taguchi and Hoffman(1996), who showed that the IMF $B_{y}$ control of the convection requires clock angles larger than

\section{SuperDARN FOV and Cluster footprint - 05:30 UT}

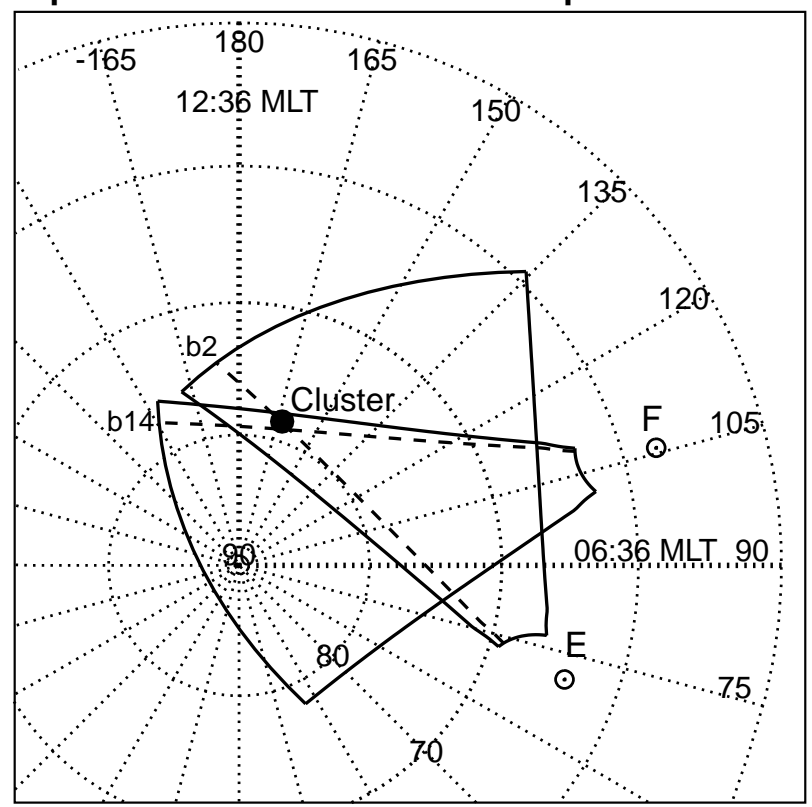

Fig. 2. Common field-of-view (magnetic coordinates) of the SuperDARN Hankasalmi (Finland: F) and Pikkvibær (Iceland East: E) radars at 05:30 UT, with the Pikkvibær beam 2 and the Hankasalmi beam 14 (dashed lines) and the Cluster footprint (black dot) superimposed.

$70^{\circ}$, we may expect a $B_{y}$ control starting around 05:25 UT and lasting up to $05: 43$ UT. The IMF clock angle rotation is also favourable to reconnection between the IMF and magnetospheric field lines at the dawnside northern magnetopause. Thus, except for the short period between $\sim 05: 30$ and $\sim 05: 45$ UT, when IMF $B_{z}<0$, the IMF and solar wind data confirm that very quiet conditions are prevailing and support the observation of a polar cusp at very high latitudes, as it will be shown from Cluster and radar data in the next section.

\section{Observations}

\subsection{High-altitude cusp}

In this section, the presentation will be organised around the CIS and FGM data, with reference to the other instruments when useful. Figure 4 presents data from CIS and FGM on board Cluster 1, for the interval 05:15-06:00 UT. The panels from top to bottom display the magnetic field amplitude, the total ion density, the ion parallel velocity, the ion perpendicular velocity projected in the $X Y$ GSE plane and the energytime spectrogram of precipitating $\mathrm{H}^{+}$ions in the $0--20^{\circ}$ pitch angle range. Figure 5 presents data from other instruments of the Cluster 1 and 3, from top to bottom, the WHISPER (SC1) electron density, the $x$ and $y$ GSE components of the electric field from EFW (SC1) and EDI (SC3), and the 
ACE IMF data : $17 / 03 / 2001$

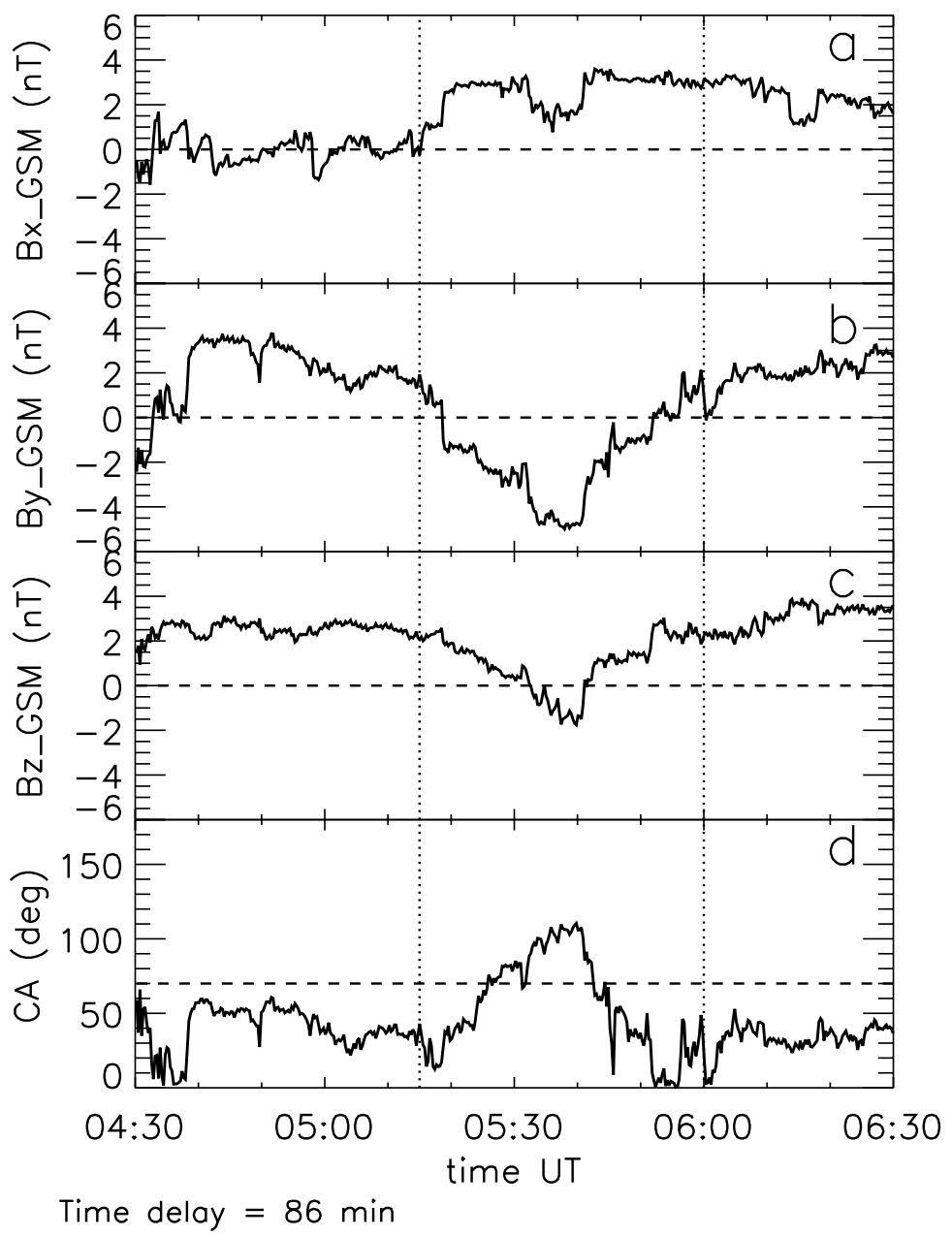

Fig. 3. Interplanetary magnetic field (IMF) from the ACE spacecraft on 17 March 2001 for the period 04:3006:30 UT. Data are lagged by $86 \mathrm{~min}$ to take into account the delay from the spacecraft to the ionosphere. Panels (a), (b) and (c) show, respectively, the IMF $B_{x}, B_{y}$ and $B_{z}$ components in GSM coordinates. Panel (d) shows the IMF clock angle.
PEACE (SC1) energy-time spectrogram of the electrons in the parallel direction.

Cluster is in the cusp from 05:05 to 06:50 UT (VontratReberac et al., 2003). During the shorter period displayed in Fig. 4, the ion density (Fig. 4b) fluctuates between 5 and $15 \mathrm{~cm}^{-3}$ and the mean ion parallel energy (Fig. 4e) is $300 \mathrm{eV}$, both values being typical of the high-altitude cusp. The PEACE data also exhibit typical cusp properties, such as an electron mean energy of $40 \mathrm{eV}$ (Fig. 5d) and essentially bidirectional electron fluxes (parallel and anti-parallel). The WHISPER electron density is of the same order and well correlated with the CIS ion density (Figs. 4b and 5a). Several characteristics of a northward IMF cusp are also observed, namely its location at very high latitude, between $79^{\circ}$ and $81^{\circ}$ MLAT (Newell et al., 1989; Palmroth et al., 2001) and the energy-time dispersion of the ion injections (VontratReberac et al., 2003).

The interval 05:25-05:54 UT can be divided into three sub-intervals, numbered 1, 2 and 3 in Figs. 4 and 5, according to the sign of the dawn-dusk component of the perpendicular ion velocity in Fig. 4 d, which closely follows the IMF $B_{y}$ variations. Before interval 1, plasma injections are observed at Cluster, with large parallel velocities. This period is associated with positive IMF $B_{y}$ and $B_{z}$ before the IMF turning. Because Cluster and SuperDARN observations are not conjugate, we will focus only on later injections observed during interval 2.

Between 05:25 and 05:36 UT (interval 1 in Figs. 4 and 5), the perpendicular convection velocity is less than $20 \mathrm{~km} \mathrm{~s}^{-1}$ and points primarily dawnward. The CIS density is low $\left(\sim 6-7 \mathrm{~cm}^{-3}\right)$ with only small fluctuations. The magnetic field amplitude is fairly steady, typical of a quiet period. These observations correspond to a transition phase in the cusp, associated with the period when the IMF is rotating from a northward-duskward orientation to a southwarddawnward orientation.

Between 05:36 and 05:46 UT (interval 2 in Figs. 4 and 5), the convection at Cluster turns duskward (in the $+Y_{G S E}$ direction). The convection velocity increases up to $50 \mathrm{~km} \mathrm{~s}^{-1}$, with numerous fluctuations in direction and amplitude. The parallel ion flux and the ion density exhibit a series of enhancements with multiple peaks. More precisely, when the 


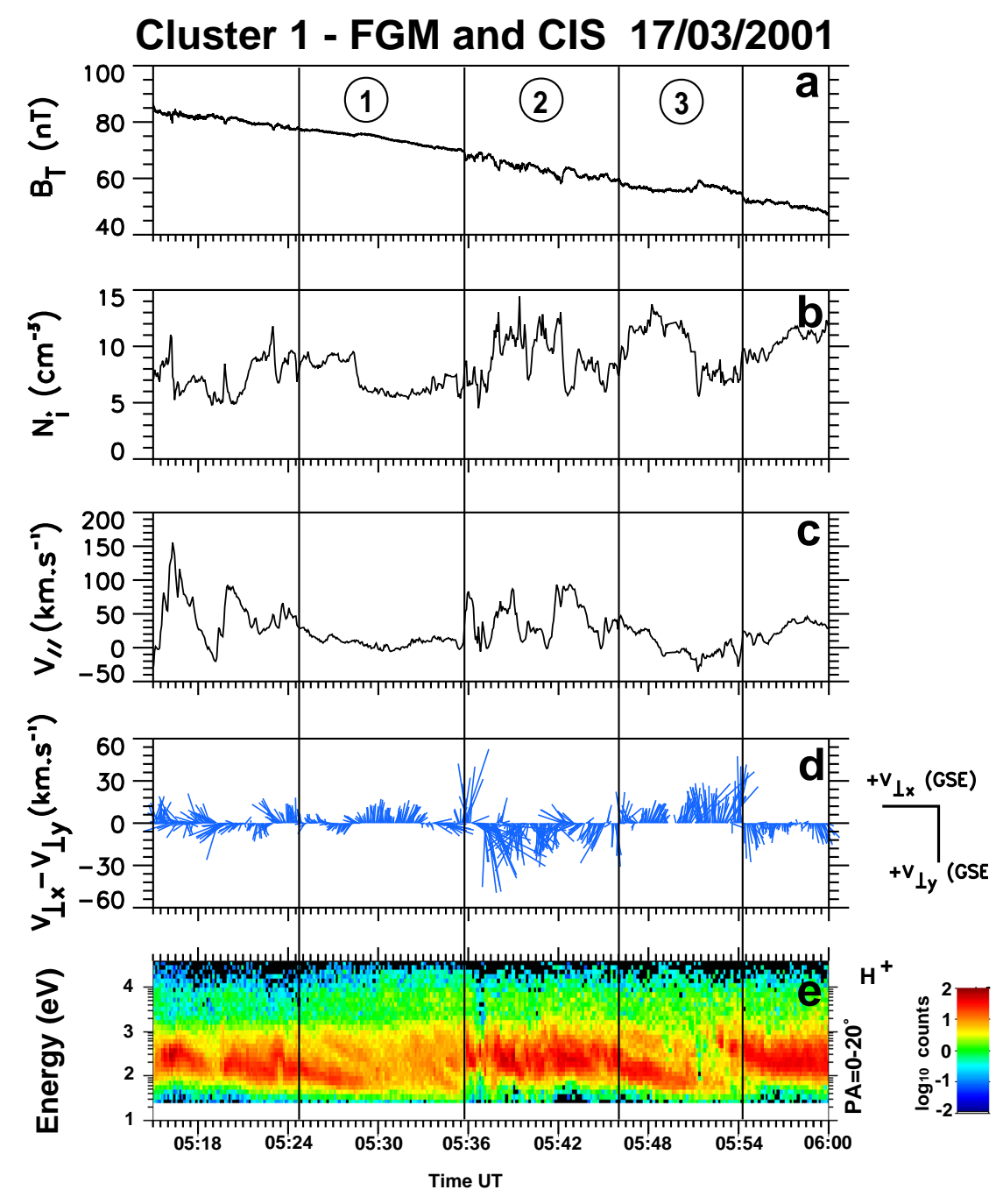

Fig. 4. Cluster 1 FGM and CIS data for the period 05:15-06:00 UT, with three sub-intervals. (a) Magnetic field amplitude. (b) Total ion density. (c) Ion parallel velocity. (d) Ion velocity vectors perpendicular to the magnetic field projected in the $X Y$ GSE plane. (e) Energy-time spectrogram of precipitating $\mathrm{H}^{+}$ions, in the $0-20^{\circ}$ pitch angle range. perpendicular velocity shows three successive duskward intensifications centred at 05:38, 05:40 and 05:43 UT, the parallel ion velocity (defined as the moment of the total ion distribution function) shows three weak downward peaks (50 and $100 \mathrm{~km} \mathrm{~s}^{-1}$ ), characteristic of an excess of precipitating ions. Notice that a first peak of parallel velocity also occurs at 05:36 UT, associated with dawnward perpendicular velocity and located at the boundary between intervals 1 and 2. Magnetic field perturbations are also observed, in particular, the magnetic field amplitude decreases during each velocity enhancement and ion injection (diamagnetic effect). These observations coincide with the period of dawnward and southward IMF, favouring the solar wind plasma entry at the dawnside magnetopause. Therefore, one can anticipate that these observations are signatures of cusp plasma injections due to magnetic reconnection.

Between 05:46 and 05:54 UT (interval 3 in Fig. 4), the perpendicular convection velocity turns dawnward again, with characteristics similar to interval 1 , but the speed remains large (around $30 \mathrm{~km} \mathrm{~s}^{-1}$ ). The density presents a largescale enhancement, the ion energies decrease slightly and the energy-time (latitude) dispersion profile is more continuous, suggesting a change in the reconnection process. In addition to the general decrease due to the motion of Cluster towards the magnetopause, the magnetic field amplitude shows a reduction followed by an enhancement, which is inverse to the density variation, implying a diamagnetic effect. This interval is associated with the return to the conditions of duskward and northward IMF. After 05:54 UT, the increase in ion energies suggests the occurrence of a new injection, and the perpendicular velocity turns duskward again for several minutes, but no apparent change in the IMF can be associated with it. All the above observations of the density and perpendicular ion velocity during intervals 1-2-3 are confirmed by the PEACE, WHISPER, EFW and EDI data: the ion and electron density profiles measured by CIS, PEACE and WHISPER (Figs. 4b and 5a) are very similar, resulting from the need to maintain quasi-neutrality in the cusp (Reiff et al., 1977; Burch, 1985). Also, the electric field measured by EFW and EDI (Fig. 5b and c) confirms the convection velocity obtained by the CIS instrument. The electric field profiles of both experiments are comparable, in spite of the 
Cluster 1 \& 3 - 17/03/2001 WHISPER sc1

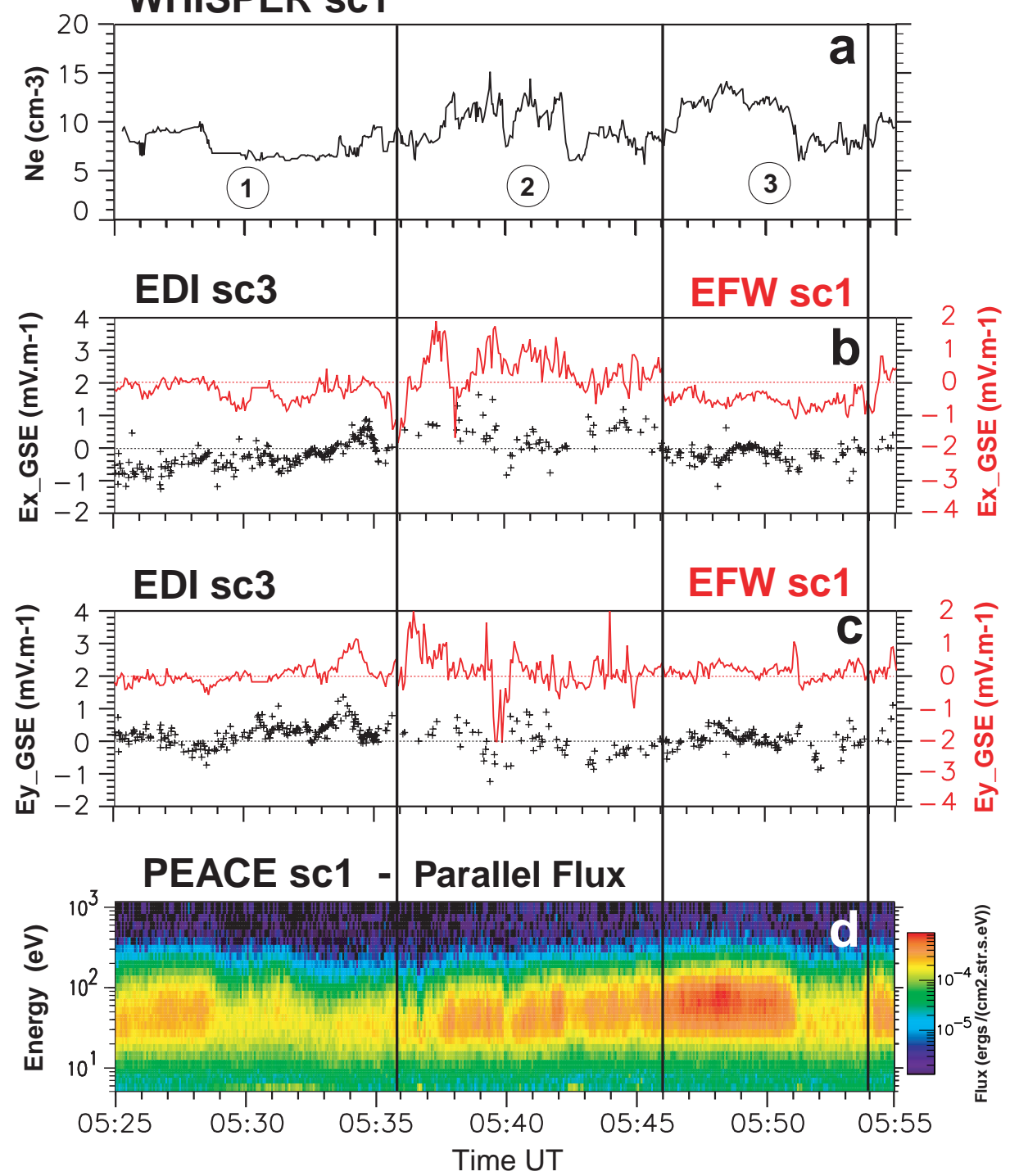

Fig. 5. WHISPER, EFW, EDI and PEACE data for the period 05:25-05:55 UT, with three sub-intervals. (a) WHISPER (SC1) electron density. (b) and (c) $x$ and $y$ components of the electric field in GSE coordinates for EFW (SC1) (red line) and EDI (SC3) (black crosses). The offset of the EFW data has been corrected. (d) PEACE (SC1) energy-time spectrogram of precipitating electrons, in the $0-20^{\circ}$ pitch angle range (Calibration 1.5).

use of spacecraft 3 for EDI with less data gaps, introducing a small lag of about 1 min between EDI and EFW. In addition, data (not shown) from the same experiment but from different satellites show similar signatures, suggesting that multipoint measurements can be used safely to deduce the velocity of propagation of the flux tubes in which injection occurs.

\subsection{Ionospheric convection}

Figure 6 presents three pairs of range-time colour-coded plots showing the ionospheric convection measured by the CUTLASS Hankasalmi and Pikkvibær radars between 05:15 and 06:15 UT. In each pair, the upper plot shows the 1-o-s velocity and the lower plot shows the amplitude $(\mathrm{dB})$ of the backscattered signal. Three beams are presented: from top to bottom, beams 13 and 14 of Hankasalmi and beam 2 of Pikkvibær. These three beams are directed mainly eastward and thus, measure essentially the dawn-dusk component of the convection velocity. The Hankasalmi beam 14 and the Pikkvibær beam 2 are the beams on which the Cluster footprint is located during this period (black and white lines in the middle and bottom panels). For both radars, the 1-o-s velocity shows cusp echoes, and the time period can be subdivided into the same three intervals as for the Cluster data. Before 05:27 UT and after 05:48-05:50 UT, the two radars 


\section{SuperDARN radial velocity and power}
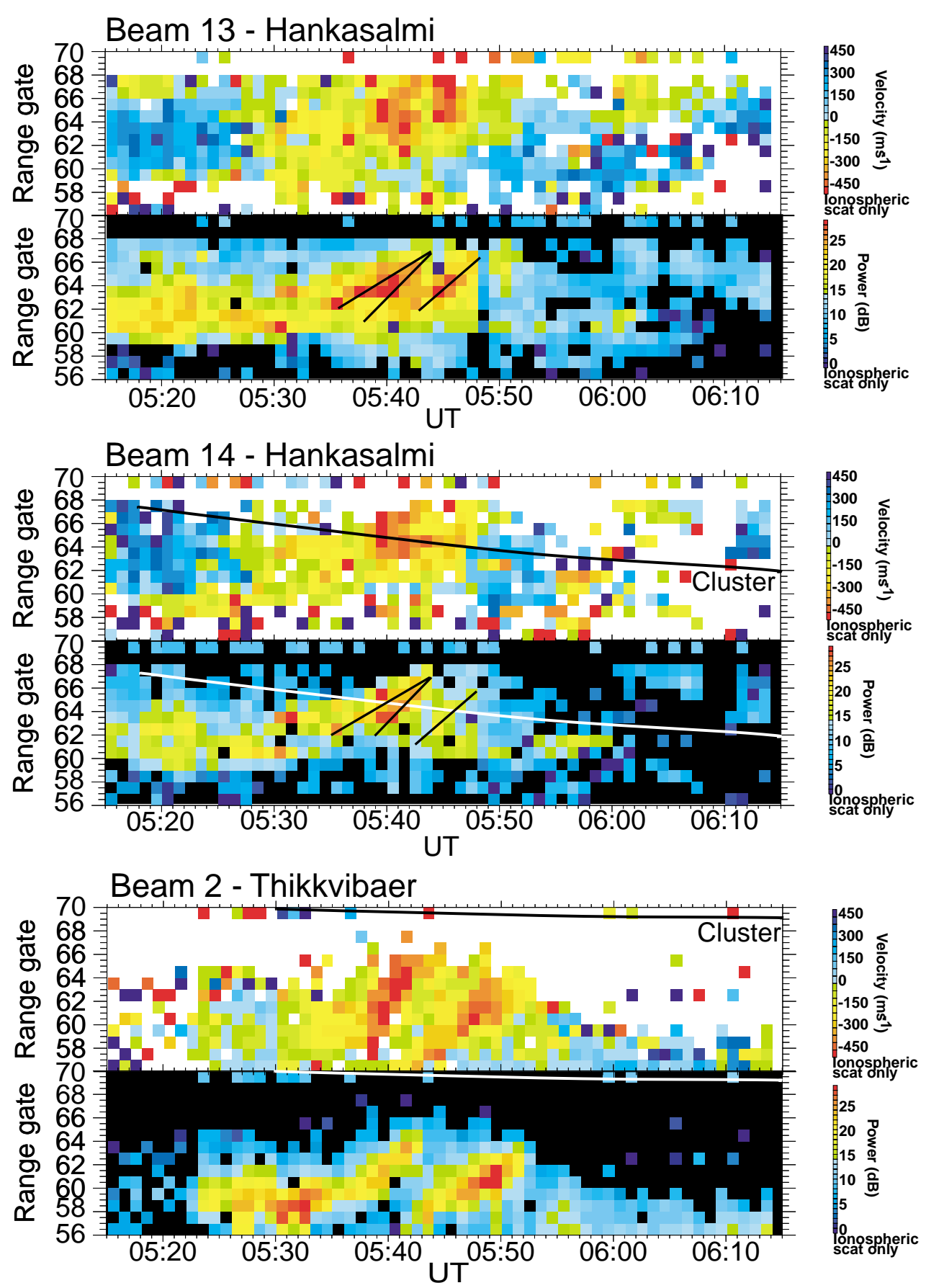

Fig. 6. Pairs of range-time plots (1-o-s velocity and backscattered power) for three beams of SuperDARN radars for the period 05:1506:15 UT. The Cluster footprint is superimposed on beam 14 of Hankasalmi and beam 2 of Pikkvibær (black or white line). The slope of the range-time dispersed structures are depicted by black segments on the power plot of the beams 13 and 14 of the Hankasalmi radar.

measure dawnward (positive) velocities associated with the periods of positive IMF $B_{y}$. Between 05:27 and 05:48 UT, i.e. during the period of stronger negative IMF $B_{y}$, they show duskward (negative) velocities. During the whole interval 05:15-06:15 UT, the plasma velocity is fairly weak, less than $600 \mathrm{~m} \mathrm{~s}^{-1}$, probably due to the quiet conditions prevailing during the overall period. The cusp echoes are located at large ranges, between 09:30 and 12:30 MLT and between $74^{\circ}$ and $82^{\circ}$ MLAT. The dawnward and southward rotation of the IMF is too short for a clear equatorward motion of the cusp echoes to be observed, as expected for a southward IMF excursion. 
During the interval of duskward convection velocity, each radar observes strong flow enhancements (flow bursts) also moving duskward, with an increased velocity. These bursts are typical ionospheric signatures of plasma injection events (Pinnock et al., 1995). Therefore, the two radars observe different flow bursts, with those of Hankasalmi being located over the Cluster footprint track, while those of Pikkvibær are closer to the radar. Then the flow bursts detected simultaneously by the two radars do not represent the same structure. This also explains why, in the range-time velocity plots of Fig. 6, the shapes of the velocity flow bursts are different for the two radars. The range-time slope of the bursts in the Pikkvibær beam clearly indicates a predominantly duskward motion of the burst, whereas no clear motion of the velocity structures is observed along the Hankasalmi beams. Although no echoes are observed by the Pikkvibær radar at the Cluster position, the flow bursts observed at closer range gates should reach the Cluster footprint after the end of the negative IMF $B_{y}$ period. On the contrary, the flow bursts observed by the Hankasalmi radar pass the Cluster position at the beginning of their lifetime during the negative IMF $B_{y}$ period. Therefore, we will later compare only the convection data from the Hankasalmi radar with Cluster. The Pikkvibær data can be used only to demonstrate the global scale of the changes in the ionospheric convection observed at the Cluster footprint by the Hankasalmi radar, and that the negative IMF $B_{y}$ period is associated with several injections.

Figure 6 also indicates that the amplitude of the backscattered signal is weak during the periods of dawnward velocity before 05:25 UT and after 05:51 UT. Between 05:25 and 05:51 UT, the amplitude increases strongly, particularly within the velocity flow bursts, possibly due to intense particle precipitation related to upward field-aligned currents. In the range-time backscattered power plots, the flow bursts are characterized by a time dispersion on both radars, contrary to the velocity structures, where no clear dispersion is seen on the Hankasalmi beams. Two structures are observed on the Pikkvibær radars and three on the Hankasalmi radars (see the three black lines in the top two panels), with the first two being hardly separated. The backscattered power is larger along the Pikkvibær beams than along the Hankasalmi beams, and the shape of the structures varies between the two radars, which again confirms that the flow bursts seen by the two radars are different. From the slope of the three power structures observed with the Hankasalmi radar, it will be possible to derive the velocity of the flow bursts structures and to compare it with the velocity of plasma structures observed at Cluster and projected into the ionosphere.

\section{Comparison between SuperDARN and Cluster}

\subsection{Plasma convection velocity}

In this section, we present a detailed comparison between the convection velocity measured in the ionosphere by $\mathrm{Su}$ perDARN and in the magnetosphere by Cluster. For map- ping the Cluster velocity into the ionosphere, magnetic field lines are assumed to be equipotential and the Tsyganenko T96 model (Tsyganenko, 1995) is used with inputs of IMF and solar wind data measured by ACE and lagged by $86 \mathrm{~min}$. Each data point of perpendicular ion velocity measured by the CIS instrument on Cluster 1 is projected along magnetic field lines into the ionosphere and then compared with $\mathrm{Su}$ perDARN radial velocities at the Cluster footprint location. We checked the validity of the T96 model by comparing the magnetic field vectors obtained by the model at the Cluster position and by the FGM instrument. The agreement is good within less than $15 \%$ in amplitude and $5^{\circ}$ in direction.

The comparison of plasma convection velocity at Cluster and SuperDARN is shown in Fig. 7. Panel (a) presents the time variation of the CIS ion perpendicular velocity in the form of vectors at the Cluster position. Each vector represents the perpendicular-to- $B$ component of the plasma convection velocity projected onto the $X Y$ GSE plane. Because the local magnetic field is close to the $z_{G S E}$ direction, the $-y_{G S E}$ component is mainly dawnward. Panel (b) shows the same data after projection into the ionosphere at $250 \mathrm{~km}$ altitude, where Vwest and Vnorth correspond to the velocity components in the magnetic west and north directions in AACGM coordinates. For comparison, panel (c) displays the range-time plot of the 1-o-s velocity for the Hankasalmi beam 14 with the Cluster footprint (black line). In order to better illustrate the correlation between the Cluster and SuperDARN velocities, the mapped CIS velocity is first averaged with a running mean over one minute (the time resolution of $\mathrm{Su}$ perDARN measurements), and then projected along the direction of the Hankasalmi beam 14 and plotted in panel (d), together with the velocity measured in the appropriate SuperDARN range gate where the Cluster footprint is located (red segments).

The correlation between satellite and radar convection velocity is satisfactory, particularly if a short delay of $2 \mathrm{~min}$ between Cluster and SuperDARN is allowed. This is the reason why the Cluster data are plotted for the 05:15-06:00 UT period (panels (a) and (b)) whereas the SuperDARN data and the SuperDARN-Cluster correlation are plotted at the ionospheric time for the 05:17-06:02 UT period (panels (c) and (d)). At the range gate of the Cluster footprint, the direction of the beam 14 of Hankasalmi is close to dawn-dusk (westeast), making positive velocities essentially dawnward and negative velocities duskward. Except for the short interval of dawnward velocities measured by Cluster between 05:35 and 05:36 UT (panels (a) and (b)) which is not observed by SuperDARN, probably because this structure is too short to be detected by SuperDARN with its 1-min resolution, SuperDARN and Cluster show the same global behaviour of the east-west component of the convection. A first dawn-to-dusk reversal at 05:34 UT (Cluster time) is followed by a step increase of the duskward velocity at 05:36 UT after which three duskward intensifications between 05:36 and 05:46 UT are associated with the injections (see below) and followed again by a dusk-to-dawn reversal at 05:46 UT. The last dawn-todusk reversal observed at Cluster at 05:56 UT is not observed 


\section{Cluster \& SuperDARN convection velocity}
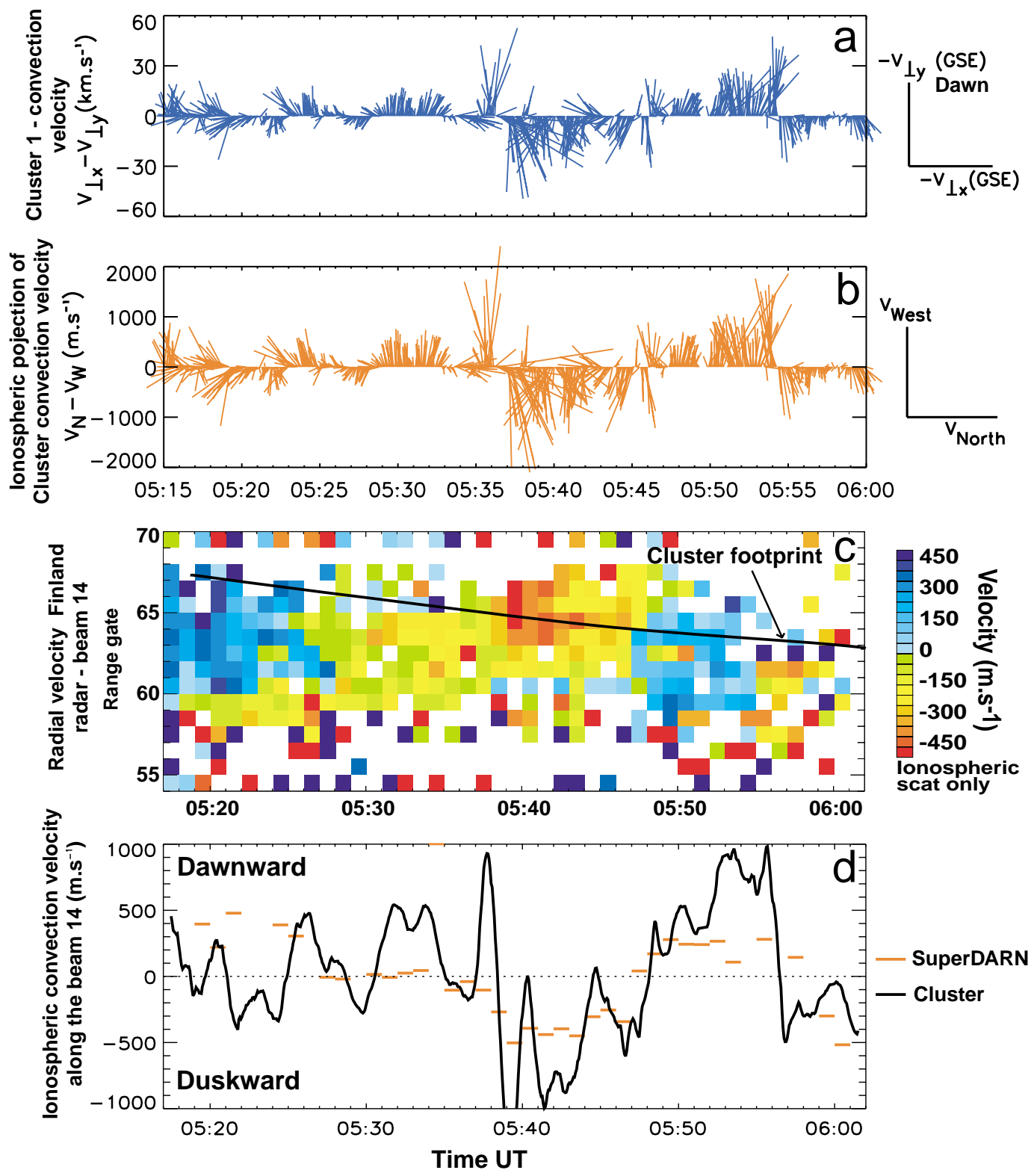

Fig. 7. Convection velocity measured by SuperDARN and Cluster. (a) Cluster 1 CIS ion perpendicular velocity vectors. Each vector represents the perpendicular-to- $B$ component of the plasma velocity projected onto the $X Y$ GSE plane. Because the local magnetic field is close to the $z_{G S E}$ direction, the $-y_{G S E}$ component is mainly dawnward. (b) Projection into the ionosphere at $250 \mathrm{~km}$ altitude of the CIS velocity vectors, where $V_{\text {west }}$ and $V_{\text {north }}$ correspond to the velocity components in the magnetic west and north directions, respectively, in AACGM coordinates. (c) Range-time plot of 1-o-s velocity for the SuperDARN Hankasalmi beam 14 with the Cluster footprint superimposed (black line). (d) Comparison of velocity measured by Cluster (solid black line) and SuperDARN (red segments). The Cluster CIS velocity has been averaged over 1 min and projected along the beam 14 of Hankasalmi. The SuperDARN velocity is the radial velocity measured at the Cluster footprint.

at the same location by SuperDARN, but about one range gate $(45 \mathrm{~km})$ westward of the Cluster footprint (panel (c)). However, this discrepancy remains within the error range, since the uncertainty of the Cluster footprint with respect to the SuperDARN pattern is as large as \pm 4 gates $( \pm 180 \mathrm{~km})$. This evaluation takes into account model-dependent uncer- tainties in mapping Cluster to the ionosphere and range uncertainties in the localization of SuperDARN echoes for large ranges. Detailed examination of the 05:36-05:46 UT interval shows that the three duskward intensifications observed by Cluster (mentioned above) are also observed by SuperDARN, although the one-minute time resolution of the radars 
Table 1. Comparison of the velocity of plasma structures (phase velocity) measured by Cluster and SuperDARN. The Cluster velocity has been deduced from FGM data (first row) and mapped into the ionosphere with T96 model (second row) and projected along beam 14 of the Hankasalmi radar (third row). The SuperDARN phase velocity is deduced from the slope of the backscattered power in the range-time plot of beam 14 of the Hankasalmi radar (bottom row). The different observation times at Cluster and at SuperDARN is due to the propagation from the magnetosphere to the ionosphere

\begin{tabular}{cccc}
\hline Cluster structures & $\begin{array}{c}\text { Burst 1 } \\
05: 38: 00 \mathrm{UT}\end{array}$ & $\begin{array}{c}\text { Burst 2 } \\
05: 39: 30 \mathrm{UT}\end{array}$ & $\begin{array}{c}\text { Burst 3 } \\
05: 42: 30 \mathrm{UT}\end{array}$ \\
\hline $\begin{array}{c}\text { High-altitude velocity } \\
\text { (from FGM data) } \\
\begin{array}{c}\text { High-altitude velocity } \\
\text { ionospheric projection } \\
\text { Velocity component }\end{array}\end{array}$ & $7.5 \mathrm{~km} \mathrm{~s}^{-1}$ & $15.4 \mathrm{~km} \mathrm{~s}^{-1}$ & $10.8 \mathrm{~km} \mathrm{~s}^{-1}$ \\
along Hankasalmi beam 14 & $395 \mathrm{~m} \mathrm{~s}^{-1}$ & $645 \mathrm{~m} \mathrm{~s}^{-1}$ & $590 \mathrm{~m} \mathrm{~s}^{-1}$ \\
\hline $\begin{array}{c}\text { SuperDARN structures } \\
\text { Burst 1 }\end{array}$ & $\begin{array}{c}\text { Burst 2 } \\
\text { 05:40:00 UT }\end{array}$ & $05: 41: 30 \mathrm{UT}$ & $05: 45: 00 \mathrm{UT}$ \\
\hline $\begin{array}{c}\text { Ionospheric velocity } \\
\text { SuperDARN data }\end{array}$ & $420 \mathrm{~m} \mathrm{~s}^{-1}$ & $710 \mathrm{~m} \mathrm{~s}^{-1}$ & $650 \mathrm{~m} \mathrm{~s}^{-1}$ \\
\hline
\end{tabular}

does not allow one to separate clearly the first two. Only the third velocity burst is clearly separated by both instruments. Moreover, during this interval of negative velocities, a general decrease in the amplitude of the velocity is also observed by both instruments. The average velocity (panel 6(d)) is systematically larger when deduced from the CIS data (up to $1000 \mathrm{~m} \mathrm{~s}^{-1}$ ) than when measured by SuperDARN (up to $600 \mathrm{~m} \mathrm{~s}^{-1}$ ). This difference can possibly be explained by the uncertainty in the mapping of the static electric field from Cluster to the ionosphere and by the fairly large spatial smoothing in the SuperDARN data.

\subsection{Velocity of plasma structures}

Independent of convection velocity, we can also compare the velocity of plasma structures (hereafter named phase velocity) observed at Cluster and the velocity of correlated plasma structures in the ionosphere. This comparison is limited to the interval of duskward convection velocity between 05:36 and 05:46 UT (Cluster time), during which welldefined plasma structures associated with the injections are detected. In the magnetosphere, the phase velocity of the plasma structures is deduced from the simultaneous fourpoint Cluster FGM data and in the ionosphere from the slope of the range-time SuperDARN power plots (Fig. 6). At the Cluster altitude, each drifting plasma structure is characterized by mostly similar magnetic and particle signatures on the four spacecraft, assuming the size of the structure is larger than the spacecraft separation $(\sim 600 \mathrm{~km})$. Magnetic signatures from FGM have been preferred because of their higher time resolution and because the magnetic field variations directly reflect the structure of the plasma injection tube (diamagnetism affecting the parallel component) and the presence of parallel currents (affecting the direction of the magnetic field) (Southwood, 1987; Lockwood et al., 2001a). However, we have checked that the phase velocity deduced by the same method, but from the electron density profiles measured by the four WHISPER instruments, is very similar (not shown). We have chosen a coordinate system in which the $z$ direction is along the mean field direction (averaged over a 2-3 min period around the event). The $x$ and $y$ directions are given by the maximum and minimum variance in the perpendicular component. Because Cluster is situated at about $8 R_{E}$, this coordinate system has been preferred to the usual $L, M, N$ system used when observations are made close to the magnetopause (Russell and Elphic, 1978).

The parallel and maximum variance components, together with the ion density and parallel velocity given by CIS, are plotted for the 05:36-05:46 UT interval in Fig. 8. Three minima are observed in the parallel component of the magnetic field (shaded zones) superposed on the large scale decrease due to the motion of the spacecraft and correlated with density maxima. Each of them is associated with a bipolar signature in the perpendicular component of the magnetic field, suggestive of a pair of field-aligned currents of opposite signs, and with a sharp gradient in the parallel velocity. All these signatures are typical of plasma injections and FTEs (Russell and Elphic, 1978; Paschmann et al., 1982).

In order to calculate the phase velocity of these three structures in the magnetosphere, we have identified similar features on each spacecraft. As an example, Fig. 9 shows the magnetic field signatures of the third event, in the direction of the mean magnetic field and in the direction of maximum perpendicular variance. Arrows on Fig. 9 show identified similar features. Assuming a plane structure with a uniform velocity through the four Cluster satellites, we determined the velocity of the plane along its normal from the time delay between the observation of similar signatures at the dif- 


\section{Cluster 1 CIS \& FGM data - 05:36-05:46 UT}

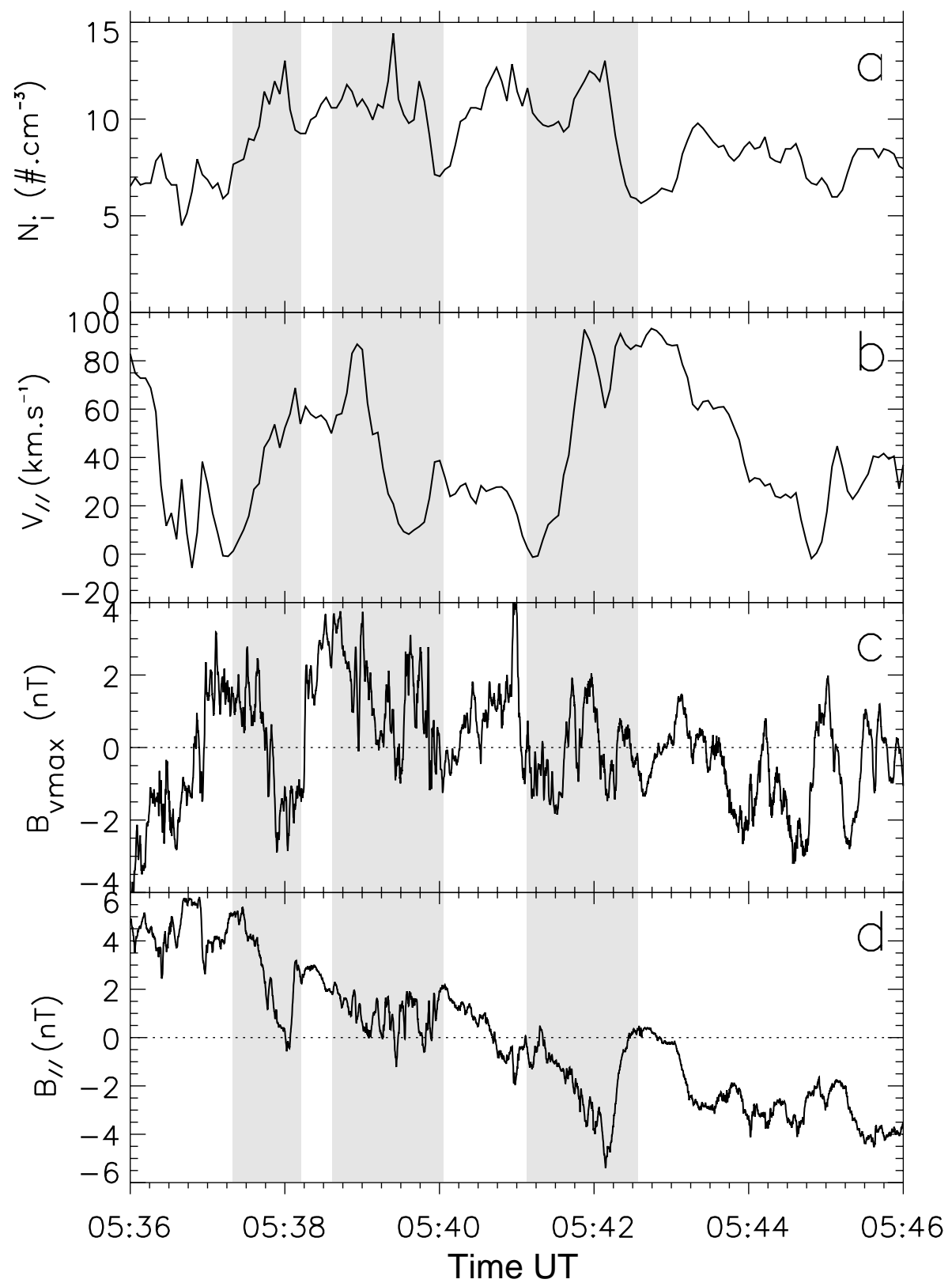

Fig. 8. Plasma injection events observed at Cluster. (a) Ion density. (b) Ion parallel velocity. (c) Perpendicular component and (d) parallel component of the magnetic field (see text).

ferent spacecraft (Dunlop et al., 2002). This perpendicular velocity is then mapped into the ionosphere with the Tsyganenko T96 model. Finally, the Cluster projected velocity is compared with the velocity of the SuperDARN ionospheric signature of the flow burst by projecting the phase velocity along the Hankasalmi beam 14 and assuming a 2-3 min delay between the structures observed by Cluster and by SuperDARN (as for the plasma convection velocity). The results are presented in Fig. 10. The top row shows for each event the phase velocity at the Cluster location in the plane perpendicular to the magnetic field, together with the relative positions of the four spacecraft. The bottom row shows the velocity projected into the ionosphere with the direction of beam 14 of the Hankasalmi radar. The first and third structures move equatorward and eastward, whereas the second structure moves essentially eastward. As it was the case for convection velocity, the Pikkvibær data cannot be used to determine a second component of the phase velocity, and therefore, we are limited to one single component, along the Hankasalmi beam 14 for the comparison. Table 1 shows the velocities at the different stages for each event. The first line gives the velocity in the magnetosphere, while the second 


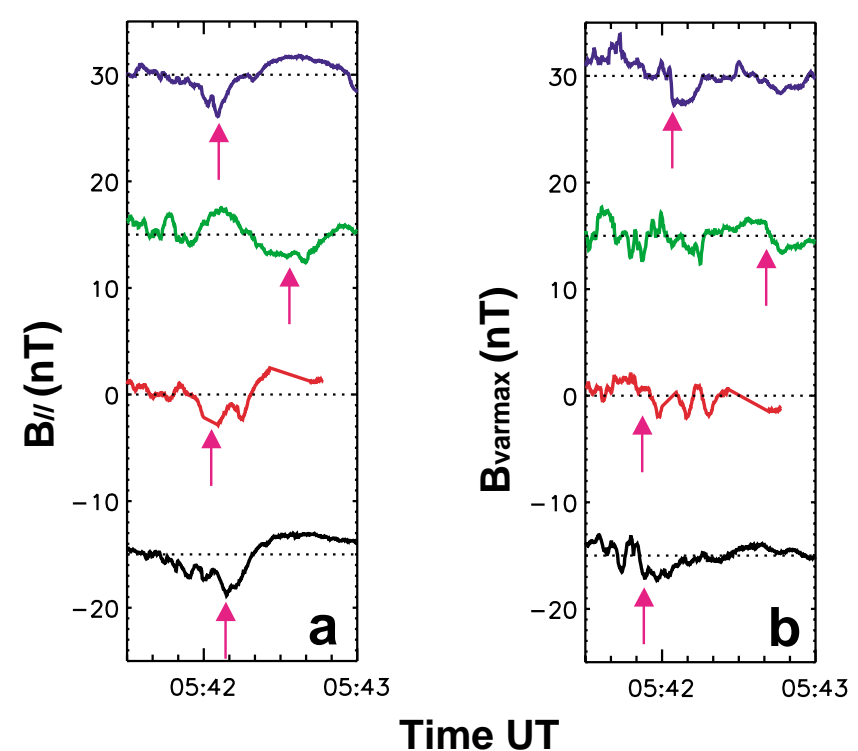

Fig. 9. Cluster magnetic field variations around the burst at 05:42:30 UT (Burst 3 of Fig. 10). (a) Parallel component. (b) Perpendicular component in the direction of maximum variance. The colour identification of the spacecraft is the same as for Fig. 1. Arrows indicate the time of observation of a similar variation at each spacecraft.

and the third lines give the velocity in the ionosphere and its component along the Hankasalmi beam 14. Notice that the apparent (phase) velocity of a plane structure along any direction is larger than the velocity along the normal to the structure. The last line gives the SuperDARN radial phase velocity obtained from a linear least-square fit to the slope of the backscattered power (Fig. 6b). Surprisingly, for all three events, the agreement between the two independent determinations of the phase velocity is excellent, owing to the large uncertainties $(\sim 20 \%)$ of each determination.

\section{Discussion}

6.1 Plasma convection velocity and phase velocity of the flow events

In the Southwood (1987) model of the ionospheric signature of FTEs, the plasma convection velocity is equal to the velocity of the flux tube, because of plasma incompressibility. Any discrepancy between these two velocities should then be attributed to a phase effect, for instance, related to the motion of the reconnection site on the magnetopause. From SuperDARN, the plasma convection velocity inside the three flow events remains relatively stable in amplitude between 350 and $500 \mathrm{~m} \mathrm{~s}^{-1}$, and the phase velocity is between 400 and $700 \mathrm{~m} \mathrm{~s}^{-1}$ (see Table 1). Therefore, the plasma convection velocity is almost equal to the phase velocity for the first flow burst and is half of it for the last two events. These results are in good agreement with those obtained by Provan et al. (1998) and particularly by McWilliams et al. (2001), who also found that during the first half of the lifetime of a pulsed ionospheric flow, its phase velocity is twice the convection velocity, with both velocities being measured in the ionosphere. The main difference between our results and the two papers listed above is that in our case, there are lower values of the plasma flow and phase velocities, which can be explained by the low solar wind pressure associated with the dominant northward IMF. On the contrary at Cluster, the plasma velocity measured by CIS appears larger than the phase velocity in two of the bursts (respectively, $25 \mathrm{~km} \mathrm{~s}^{-1}$ and $20 \mathrm{~km} \mathrm{~s}^{-1}$ in bursts 2 and 3) and slightly smaller in burst 1. So, the mean ratio between the plasma velocity and the phase velocity reverses between Cluster and the ionosphere. However, this result must be considered with care, owing to the fairly large uncertainty of the phase velocity determinations. Furthermore, the bursts observed at Cluster are characterised by large gradients in the plasma velocity.

\subsection{Flow events dimensions}

Here, we evaluate and compare the ionospheric dimensions of the three flow events. Using the power data of the Hankasalmi radar, and by identifying the number of beams, as well as the number of gates for each beam where the structures are observed, the north-south and east-west dimensions of the flux tubes can be obtained. Since the structures are observed on 2 beams and on 1 or 2 gates for each beam, their typical dimensions are about $300 \mathrm{~km}$ in the north-south direction and $45-90 \mathrm{~km}$ in the east-west direction. Although these ionospheric dimensions are characteristic of reconnected flux tubes, the north-south elongation of the structures are unusual (Provan et al., 1998; McWilliams et al., 2001). Because the structures are moving in the east-west direction, the flow events move over the Cluster satellites along their smaller dimension. This result supports the hypothesis of a plane structure used for the determination of the phase velocity at Cluster. At the Cluster altitude, the east-west smaller dimension of the reconnected flux tubes can be evaluated to $\sim 700-1500 \mathrm{~km}$ (given by the product of the phase velocity of the structure by the time during which Cluster remains inside the structure). Now, we can compare the east-west dimension of each ionospheric structure observed by the radar with the dimension deduced from Cluster data and mapped into the ionosphere. The ionospheric dimension in the east-west direction of each injection, as deduced from Cluster data, is $\sim 30 \mathrm{~km}$ for the first, $\sim 60 \mathrm{~km}$ for the second, and $\sim 40 \mathrm{~km}$ for the third. These dimensions are slightly smaller than those determined from the SuperDARN data, but owing to their poor spatial resolution, the comparison is quite satisfactory and adds consistency to the comparison between the convection and phase velocities made in the previous sections.

6.3 Global ionospheric convection and location of the reconnection site

In order to replace the previous results with respect to the large-scale ionospheric flow pattern and then to infer the lo- 


\section{Cluster \& SuperDARN phase velocity of the structures}
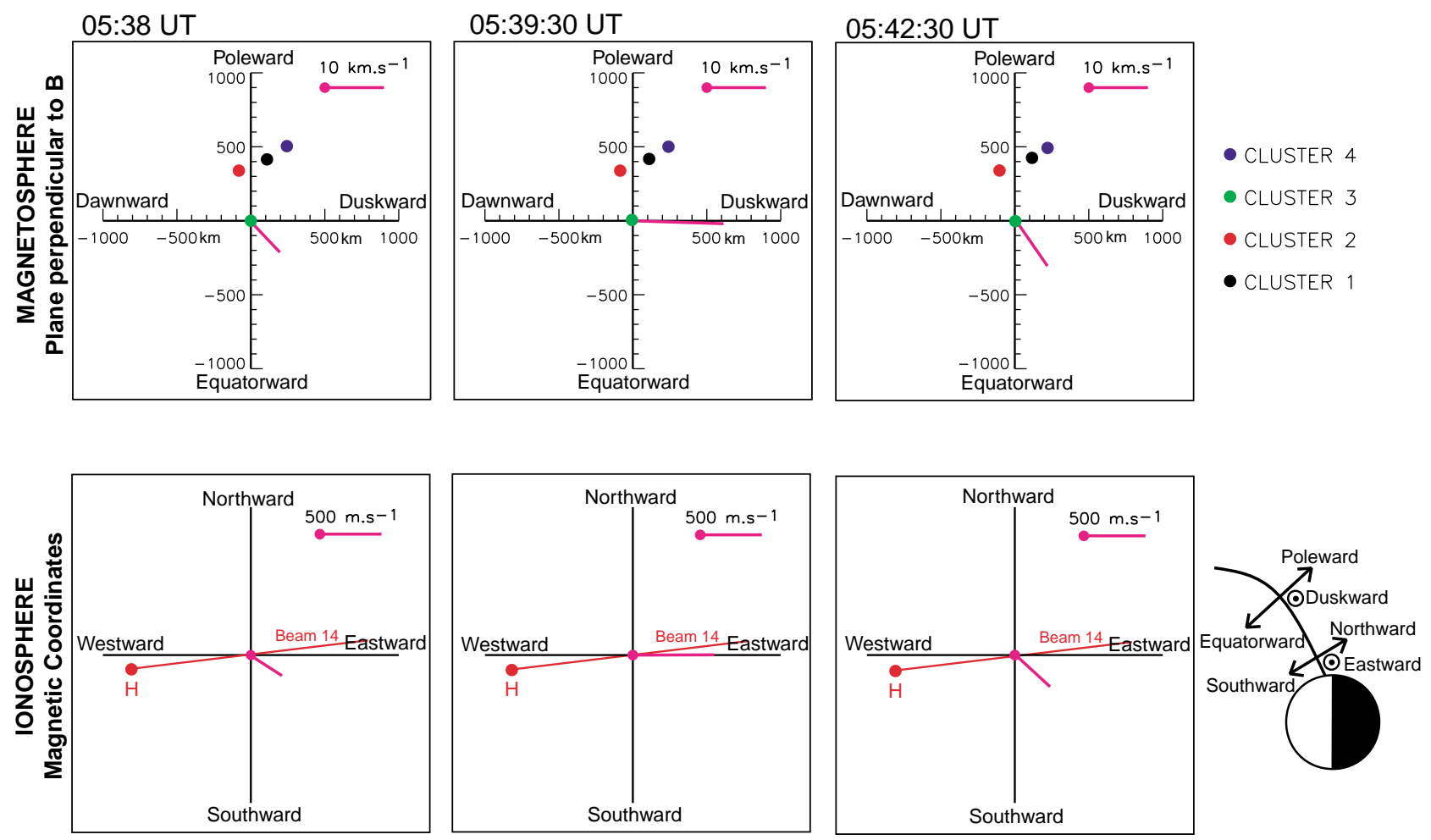

Fig. 10. Phase velocity vector of three injections events determined from Cluster FGM and associated with flow bursts observed by SuperDARN. Top: at the Cluster location in the plane perpendicular to the magnetic field and in GSE coordinates with the relative position of the four spacecraft. Bottom: projection of the Cluster velocity into the ionosphere in AACGM coordinates. The direction of beam 14 of the Hankasalmi radar at the Cluster footprint is also shown.

cation of the reconnection site, we have employed the "map potential" technique developed by Ruohoniemi and Baker (1998). This technique yields large-scale global convection maps from the 1-o-s velocity measurements by multiple radars, via mathematical fitting of the data, to an expansion of the electrostatic potential in spherical harmonics. First, the l-o-s data are filtered and then mapped onto a polar grid. These "gridded" measurements are then used to determine the most consistent electrostatic potential distribution. The iso-potential lines represent the plasma streamlines of the convection. Since 1-o-s velocity measurements are not always available, information from the statistical model of Ruohoniemi and Greenwald (1996), parameterised by IMF conditions, is used to stabilise the solution where no measurements are made. Two of these global maps are plotted in Fig. 11 to show the variations of the global ionospheric convection.

During the interval 04:40-05:25 UT, when the IMF $B_{y}$ and $B_{z}$ are positive, before the observations described in this paper, the Cluster footprint is located close to the Hankasalmi radar echoes, and both instruments observe repeated plasma injection signatures. These injections observed by Cluster were already mentioned in Sect. 4.2. The global convection map at 05:03-05:04 UT (Fig. 11a) shows an almost circu- lar clockwise cell, centred close to the magnetic pole. The convection velocity is largest in the dawn sector between 06:00 and 12:00 MLT. The plasma in the cusp region around noon is purely dawnward, indicating the strong control of the dayside convection by the positive IMF $B_{y}$ component. Since the IMF $B_{z}$ component is positive, this central cell can be the lobe cell driven by reconnection on the high-latitude magnetopause, tailward of the cusp region, as expected from the anti-parallel merging concept of the associated three-cell model of Cowley and Lockwood (1992) for positive IMF $B_{y}$ and $B_{z}$. From this model, the reconnection site is probably located on the dusk side of the northern lobe. Two classical viscous cells are also expected on both sides of a single lobe cell. In Fig. 11a, only the dawn side cell is clearly observed, probably because very few radar echoes are obtained on the dusk side ionosphere below $75^{\circ}$ MLAT. The reduced size of the polar cap and the small convection velocity, both due to the northward IMF, can explain why the radars do not detect the sunward return flow on the equatorward sides of the two viscous cells expected around $75^{\circ}$ MLAT, between 03:00 and 09:00 MLT on the morningside and between 15:00 and 21:00 MLT on the eveningside.

Between 05:27 and 05:37 UT, an important reorganisation of the convection occurs, with a strong decrease in the plasma 


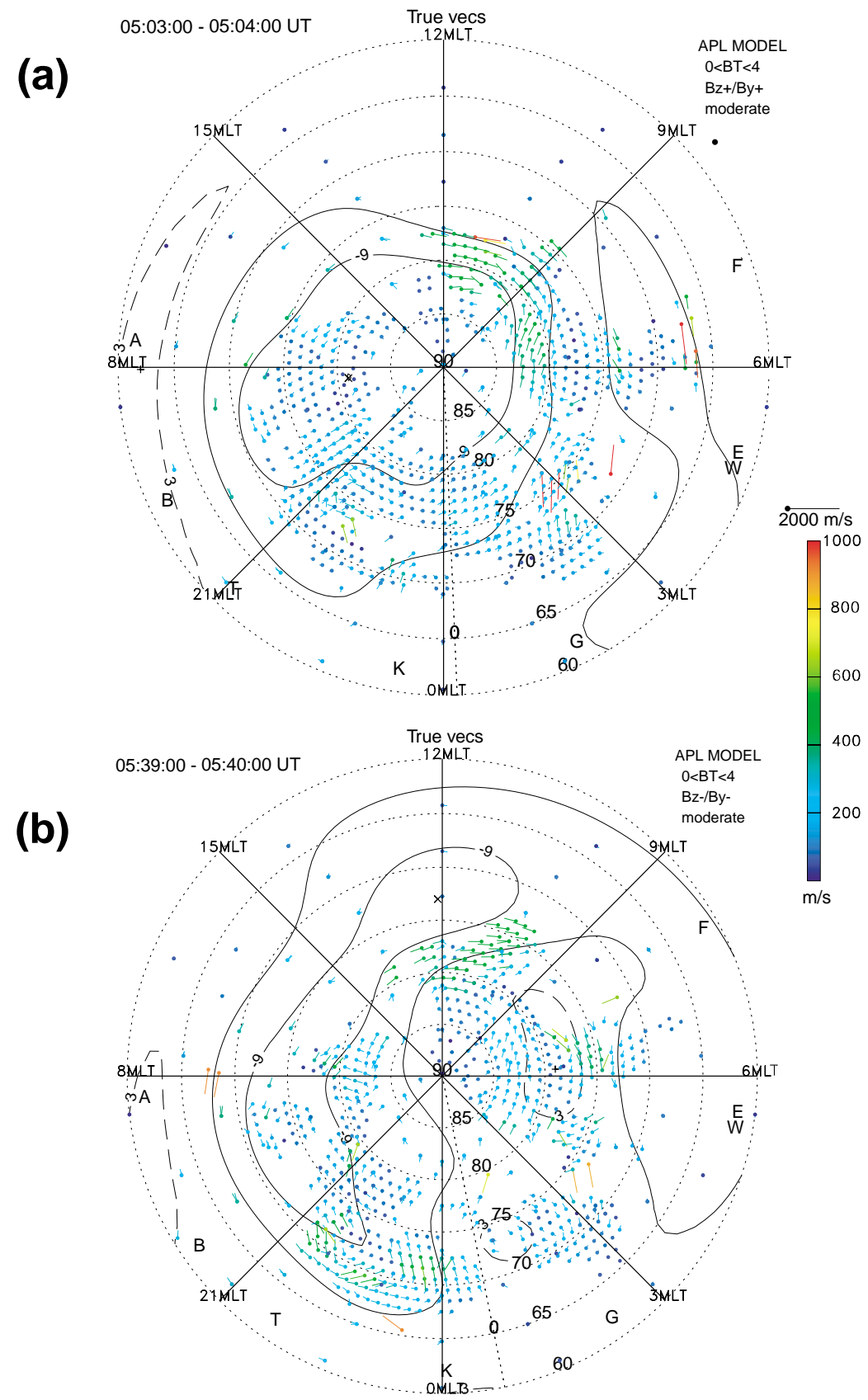

Fig. 11. Global convection velocity maps deduced from SuperDARN data of the Northern Hemisphere radars according to the method of Ruohoniemi and Baker (1998), at two selected times for (a) IMF $B_{y}>0$ and (b) IMF $B_{y}<0$. The black solid lines represent the equipotential contours and the colour dots represent the grid points where the convection vectors are determined.

velocity in the cusp region, probably associated with the $B_{y}$ turning, which is observed both by SuperDARN (not shown) and Cluster (Vontrat-Reberac et al., 2003). Then between 05:37 and 05:48 UT, during the time interval studied in this paper, the convection velocity in the cusp increases again but the ionospheric flow turns suddenly duskward, as shown by the global convection map at 05:39-05:40 UT in Fig. 11b. In particular, the flow bursts in the polar cusp are injected in the pre-noon sector between 11:00 and 12:00 MLT and are dragged duskward. Moreover, a large duskside cell is also observed with a clear crescent-shape due to magnetic tension effect. These observations confirm that even during this pe- riod of negative $B_{z}$, the global dayside convection continues to be controlled by the IMF $B_{y}$. Several other characteristics are in agreement with a negative IMF $B_{z}$, such as the lower latitude $\left(74^{\circ} \mathrm{MLAT}\right)$ of the flow bursts appearance, the global convection pattern extending to slightly lower latitudes in the dayside and displaying the well-known two-cell circulation. These observations support a reconnection on the low-latitude dayside magnetopause. However, the phase velocity of two of the flow bursts determined from Cluster data (Fig. 10) shows a southward component, which could be interpreted as indicating a reconnection site on the highlatitude magnetopause, tailward of the cusp (Maezawa, 1976; 
Crooker, 1979; Sandholt et al., 1992). A possibility is that because the convection is clearly controlled by the IMF $B_{y}$, the reconnection site could be located on the dawn flank of the magnetopause $\left(\left|B_{y}\right|>\left|B_{z}\right|\right)$ (Crooker, 1979, 1988) and neither on the high- nor on the low-latitude magnetopause.

After 05:48 UT, the convection velocity in the cusp turns dawnward again. A clockwise central cell reappears with the same characteristics as during the interval 04:40-05:27 UT, confirming the return to a positive IMF $B_{y}$ and $B_{z}$ convection pattern and a reconnection site on the high-latitude magnetopause.

\section{Conclusion}

A conjunction between the Cluster spacecraft in the dayside external cusp and the SuperDARN radars in the ionosphere allows one to compare the plasma convection velocity and the drift velocity of plasma injection structures at the two locations. We have first compared convection velocity in the magnetosphere and in the ionosphere. The convection pattern is dominated by the IMF $B_{y}$ component and reacts almost instantaneously to its variations. The comparison between the convection directions at both locations is satisfactory, if one assumes a $2-3$ min delay between the cusp at $7-8 R_{E}$ altitude and the ionosphere. The convection velocity measured at Cluster after mapping into the ionosphere, is systematically about 1.5 times larger than at SuperDARN, but the relative variations are at both locations very consistent.

The most important result is the clear one-to-one correlation observed between three successive particle injection structures, each associated with magnetic bipolar signatures typical of FTEs, and three subsequent bursts of enhanced convection observed in the ionosphere. The best correlation is achieved when a time delay of $2-3 \mathrm{~min}$ is applied between the 7-8 $R_{E}$ altitude and the ionosphere. Evaluation of the drift (phase) velocity at Cluster $\left(7.5-15 \mathrm{~km} \mathrm{~s}^{-1}\right.$, or $400-600 \mathrm{~m} \mathrm{~s}^{-1}$ when mapped into the ionosphere) and of the phase velocity of the associated flow bursts in the ionosphere gives similar results. From SuperDARN measurements, depending on the flow bursts, the phase velocity varies from equal to twice the convection velocity and is in agreement with previous works (Provan et al., 1998; McWilliams et al., 2001). On the contrary at Cluster, the phase velocity is smaller than the convection velocity. The size of reconnected flux tubes at Cluster and of their elongated counterpart in the ionosphere has been evaluated. From SuperDARN HF radar, the size at ionospheric altitudes is of the order of $45-90 \mathrm{~km}$ in the east-west direction and elongated up to $\sim 300 \mathrm{~km}$ in the north-south direction. The ionospheric east-west dimensions evaluated at Cluster are consistent, although smaller (30-60 km). Thus, we may suggest that, during a $\sim 15$-min interval of IMF pointing southward-dawnward, simultaneous magnetospheric transient observations at Cluster, i.e. sporadic particle injections within newly-opened flux tubes moving eastward, and in the ionosphere, i.e. transient flow bursts moving duskward, are related signatures of a pulsed magnetic reconnection occurring on the dawn flank of the magnetopause.

Acknowledgements. The authors are grateful to the Principal Investigators, A. Balogh, (FGM), A. Fazakerley (PEACE), G. Gustafsson (EFW), G. Paschmann (EDI) and, H. Rème (CIS), for providing the Cluster data. The authors acknowledge A. Vontrat-Reberac for helpful discussions. The CUTLASS HF radars are deployed and operated by the University of Leicester, and are jointly funded by the UK Particle Physics and Astronomy Research Council (grant number PPA/R/R/1997/00256), the Finnish Meteorological Institute, and the Swedish Institute of Space Physics. The authors acknowledge the principal investigator N. Ness and the ACE Science Center for providing the ACE magnetic field data.

Topical Editor T. Pulkkinen thanks two referees for their help in evaluating this paper.

\section{References}

Aparicio, B., Thelin, B., and Lundin, R.: The polar cusp from a particle point of view: a statistical study based on Viking data, J. Geophys. Res., 96, 14 023-14 031, 1991.

Baker, K. B. and Wing, S.: A new magnetic coordinate system for conjugate studies at high latitudes, J. Geophys. Res., 94, 91399143, 1989.

Balogh, A., Carr, C. M., Acuña, M. H., Dunlop, M. W., Beek, T. J., Brown, P., Fornaçon, K.-H., Georgescu, E., Glassmeier, K.H., Harris, J., Musmann, G., Oddy, T., and Schwingenschuh, K.: The CLUSTER Magnetic Field Investigation: overview of in-flight performance and initial results, Ann. Geophysicae, 19, 1207-1217, 2001.

Berchem, J. and Russell, C. T.: Flux transfer events on the magnetopause: spatial distribution and controlling factors, J. Geophys. Res., 89, 6689-6703, 1984.

Bosqued, J. M., Phan, T. D., Dandouras, I., Escoubet, C. P., Rème, H., Balogh, A., Dunlop, M. W., Alcaydé, D., Amata, E., Bavassano-Cattaneo, M.-B., Bruno, R., Carlson, C., DiLellis, A. M., Eliasson, L., Formisano, V., Kistler, L. M., Klecker, B., Korth, A., Kucharek, H., Lundin, R., McCarthy, M., McFadden, J. P., Möbius, E., Parks, G. K., and Sauvaud, J.-A.: CLUSTER observations of the high-latitude magnetopause and cusp: initial results from the CIS ion instruments, Ann. Geophysicae, 19, 1545-1566, 2001.

Burch, J. L.: Quasi-neutrality in the polar cusp, Geophys. Res. Lett., 12, 469-472, 1985.

Cowley, S. W. H., Morelli, J. P., and Lockwood, M.: Dependence of convective flows and particle precipitation in the high-latitude dayside ionosphere on the $X$ and $Y$ components of the interplanetary magnetic field, J. Geophys. Res., 96, 5557-5564, 1991.

Cowley, S. W. H. and Lockwood, M.: Excitation and decay of solar wind-driven flows in the magnetosphere-ionosphere system, Ann. Geophysicae, 10, 103-115, 1992.

Crooker, N. U.: The magnetospheric boundary layers: a geometrically explicit model, J. Geophys. Res., 82, 3629-3633, 1977.

Crooker, N. U.: Dayside merging and cusp geometry, J. Geophys. Res., 84, 951-959, 1979.

Crooker, N. U.: Mapping the merging potential from the magnetopause to the ionosphere through the dayside cusp, J. Geophys. Res., 93, 7338-7344, 1988. 
Décréau, P. M. E., Fergeau, P., Krasnoselskikh, V., Le Guirriec, E., Lévêque, M., Martin, Ph., Randriamboarison, O., Rauch, J. L., Sené, F. X., Séran, H. C., Trotignon, J. G., Canu, P., Cornilleau, N., de Féraudy, H., Alleyne, H., Yearby, K., Mögensen, P. B., Gustafsson, G., André, M., Gurnett, D. C., Darrouzet, F., Lemaire, J., Harvey, C. C., Travnicek, P., and Whisper experimenters: Early results from the Whisper instrument on Cluster: an overview, Ann. Geophysicae, 19, 1241-1258, 2001.

Dunlop, M. W., Balogh, A., and Glassmeier, K.-H.: Fourpoint Cluster application of magnetic field analysis tools: the discontinuity analyzer, J. Geophys. Res., 107, 1385, doi:10.1029/2001JA005089, 2002.

Eastman, T. E., Hones, Jr., E. W., Bame, S. J., and Asbridge, J. R.: The magnetospheric boundary layer: site of plasma, momentum and energy transfer from the magnetosheath into the magnetosphere, Geophys. Res. Lett., 3, 685-688, 1976.

Elphic, R. C., Lockwood, M., Cowley, S. W. H., and Sandholt, P. E.: Flux Transfer Events at the magnetopause and in the ionosphere, Geophys. Res. Lett., 17, 2241-2244, 1990.

Etemadi, A., Cowley, S. W. H., Lockwood, M., Bromage, B. J. I., and Willis, D. M.: The dependence of high-latitude dayside ionospheric flows on the north-south component of the IMF - A high time resolution correlation analysis using EISCAT 'Polar' and AMPTE UKS and IRM data, Planet. Space. Sci., 36, 471-498, 1988.

Farrugia, C. J., Rijnbeek, R. P., Saunders, M. A., Southwood, D. J., Rodgers, D. J., Smith, M. F., Chaloner, C. P., Hall, D. S., Christiansen, P. J., and Woolliscroft, L. J. C.: A multi-instrument study of flux transfer event structure, J. Geophys. Res., 93, 14465 14477,1988

Fuselier, S. A., Lockwood, M., Onsager, T. G., and Peterson, W. K.: The source population for the cusp and cleft/LLBL for southward IMF, Geophys. Res. Lett., 26, 1665-1668, 1999.

Goertz, C. K., Nielsen, E., Korth, A., Glassmeier, K.-H., Haldoupis, C., Hoeg, P., and Hayward, D.: Observations of a possible ground signature of flux transfer events, J. Geophys. Res., 90, 4069-4078, 1985.

Greenwald, R. A., Baker, K. B., Dudeney, J. R., Pinnock, M., Jones, T. B., Thomas, E. C., Villain, J.-P., Cerisier, J.-C., Senior, C., Hanuise, C., Hunsucker, R. D., Sofko, G., Koehler, J., Nielsen, E., Pellinen, R., Walker, A. D. M., Sato, N., and Yamagishi, H.: Darn/SuperDARN: a global view of the dynamics of highlatitude convection, Space Sci. Rev., 71, 761-796, 1995.

Gustafsson, G., André, M., Carozzi, T., Eriksson, A. I., Fälthammar, C.-G., Grard, R., Holmgren, G., Holtet, J. A., Ivchenko, N., Karlsson, T., Khotyaintsev, Y., Klimov, S., Laakso, H., Lindqvist, P.-A., Lybekk, B., Marklund, G., Mozer, F., Mursula, K., Pedersen, A., Popielawska, B., Savin, S., Stasiewicz, K., Tanskanen, P., Vaivads, A., and Wahlund, J.-E.: First results of electric field and density observations by Cluster EFW based on initial months of operation, Ann. Geophysicae, 19, 1219-1240, 2001.

Haerendel, G., Paschmann, G., Sckopke, N., Rosenbauer, H., and Hedgecock, P. C.: The frontside boundary layer of the magnetopause and the problem of reconnection, J. Geophys. Res., 83, 3195-3216, 1978.

Johnstone, A. D., Alsop, C., Burge, S., et al.: 'PEACE: a Plasma electron and current experiment', Space Sci. Rev., 79, 351-398, 1997.

Lockwood, M., Cowley, S. W. H., Sandholt, P. E., and Lepping, R. P.: The ionospheric signatures of flux transfer events and solar wind dynamic pressure changes, J. Geophys. Res., 95, 17113
$17135,1990$.

Lockwood, M. and Smith, M. F.: The variation of reconnection rate at the dayside magnetopause and cups ion precipitation, J. Geophys. Res., 97, 14 841-14 847, 1992.

Lockwood, M., Milan, S. E., Onsager, T., Perry, C. H., Scudder, J. A., Russell, C. T., and Brittnacher, M.: Cusp ion steps, filedaligned currents and poleward auroral forms, J. Geophys. Res. 106, 29 555-29 569, 2001a.

Lockwood, M., Opgenoorth, H. J., van Eyken, A. P., et al.: Coordinated Cluster, ground-based instrumentation and low-altitude satellite observations of transient poleward-moving events in the ionosphere and in the tail lobe, Ann. Geophysicae, 19, 15891612, 2001b.

Lockwood, M., Fazerkerley, A., Opgenoorth, H. J., et al.: Coordinated Cluster and ground-based instrument observations of transient changes in the magnetopause boundary layer during an interval of predominantly northward IMF: relation to reconnection pulses and FTE signatures, Ann. Geophysicae, 19, 1613-1640, 2001c.

Maezawa, K.: Magnetospheric convection induced by the positive and negative $Z$ components of the interplanetary magnetic field: quantitative analysis using polar cap magnetic records, J. Geophys. Res., 81, 2289-2303, 1976.

McWilliams, K. A., Yeoman, T. K., and Provan, G.: A statistical survey of dayside pulsed ionospheric flows as seen by the CUTLASS Finland HF radar, Ann. Geophysicae, 18, 445-453, 2000.

McWilliams, K. A., Yeoman, T. K., and Cowley, S. W. H.: Twodimensional electric field measurements in the ionospheric footprint of a flux transfer event, Ann. Geophysicae, 18, 1584-1598, 2001.

Milan, S. E., Lester, M., Cowley, S. W. H., and Brittnacher, M.: Convection and auroral response to a southward turning of the IMF: Polar UVI, CUTLASS, and IMAGE signatures of transient magnetic flux transfer at the magnetopause, J. Geophys. Res., 105, 15 741-15 755, 2000.

Neudegg, D. A., Yeoman, T. K., Cowley, S. W. H., Provan, G., Haerendel, G., Baumjohann, W., Auster, U., Fornaçon, K.-H., Georgescu, E., and Owen, C. J.: A flux transfer event observed at the magnetopause by the Equator-S spacecraft and in the ionosphere by the CUTLASS HF radar, Ann. Geophysicae, 17, 707$711,1999$.

Neudegg, D. A., Cowley, S. W. H., Milan, S. E., Yeoman, T K., Lester, M., Provan, G., Haerendel, G., Baumjohann, W., Nikutowski, B., Büchner, J., Auster, U., Fornaçon, K.-H., and Georgescu, E.: A survey of magnetopause FTEs and associated flow bursts in the polar ionosphere, Ann. Geophysicae, 18, 416435, 2000

Newell, P. T. and, Meng, C.-I.: The cusp and the cleft/boundary layer: low-altitude identification and statistical local time variation, J. Geophys. Res., 93, 14 549-14 556, 1988.

Newell, P. T., Meng, C.-I., Sibeck, D. G., and, Lepping, R.: Some low-altitude cusp dependencies on the interplanetary magnetic field, J. Geophys. Res., 94, 8921-8927, 1989.

Opgenoorth, H. J., Lockwood, M., Alcadé,D., et al.: Coordinated ground-based, low altitude satellite and Cluster observations on global and local scales during a transient post-noon sector excursion of the magnetospheric cusp Ann. Geophysicae, 19, 13671398, 2001.

Owen, C. J., Fazakerley, A. N., Carter, P. J., Coates, A. J., Krauklis, I. C., Szita, S., Taylor, M. G. G. T., Travnicek, P., Watson, G., Wilson, R. J., Balogh, A., and Dunlop, M. W.: CLUSTER PEACE observations of electrons during magnetosheric 
flux transfer events, , Ann. Geophysicae, 19, 1509-1522, 2001.

Palmroth, M., Lakso, H., and Pulkkinen, T.: Location of highaltitude cusp during steady solar wind conditions, J. Geophys. Res., 110, 21 109-21 122, 2001.

Paschmann, G., Haerendel, G., Sckopke, N., and Rosenbauer, H.: Plasma and magnetic feild characteristics of the distant polar cusp near local noon: the entry layer, J. Geophys. Res., 81, 2883 2899, 1976.

Paschmann, G., Haerendel, G., Papamastorakis, I., Sckopke, N., Bame, S. J., Gosling, J. T., and Russell, C. T.: Plasma and magnetic field characteristics of magnetic flux transfer events, J. Geophys. Res., 87, 2159-2168, 1982.

Paschmann, G., Quinn, J. M., Torbert, R. B., Vaith, H., McIlwain, C. E., Haerendel, G., Bauer, O. H., Bauer, T., Baumjohann, W., Fillius, W., Förster, M., Frey, S., Georgescu, E., Kerr, S. S., Kletzing, C. A., Matsui, H., Puhl-Quinn, P., and Whipple, E. C.: The Electron Drift Instrument on Cluster: overview of first results, Ann. Geophysicae, 19, 1273-1288, 2001.

Pinnock, M., Rodger, A. S., Dudeney, J. R., Greenwald, R. A., Baker, K. B., and Ruohoniemi, J. M.: An ionospheric signature of possible enhanced magnetic field merging on the dayside magnetopause, J. Atmos. Terr. Phys., 53, 201-212, 1991.

Pinnock, M., Rodger, A. S., Dudeney, J. R., Baker, K. B., Newell, P. T., Greenwald, R. A., and Greenspan, M. E.: Observations of an enhanced convection channel in the cusp ionosphere, J. Geophys. Res., 98, 3767-3776, 1993.

Pinnock, M., Rodger, A. S., Dudeney, J. R., Rich, F., and Baker, K. B.: High spatial and temporal resolution observations of the ionospheric cusp, Ann. Geophysicae, 13, 919-925, 1995.

Provan, G., Yeoman, T. K., and Milan, S. E.: CUTLASS Finland radar observations of the ionospheric signature of flux transfer events and the resulting plasma flow, Ann. Geophysicae, 16, 1411-1422, 1998.

Provan, G. and Yeoman, T. K.: Statistical observations of the MLT, latitude and size of pulsed ionospheric flows with the CUTLASS Finland radar, Ann. Geophysicae, 17, 855-867, 1999.

Provan, G., Yeoman, T. K., and Cowley, S. W. H.: The influence of the IMF $B_{y}$ component on the location of pulsed flows in the dayside ionosphere observed by an HF radar, Geophys. Res. Lett., 26, 521-524, 1999.

Reiff, P. H. and Burch, J. L.: IMF $B_{y}$-dependent plasma flow and birkeland currents in the dayside magnetosphere, 2. A global model for northward and southward IMF, J. Geophys. Res., 90, 1595-1609, 1985.

Reiff, P. H., Hill, T. W., and Burch, J. L.: Solar wind injection at the dayside magnetospheric cusp, J. Geophys. Res., 82, 479-491, 1977.

Rème H., Aoustin, C., Bosqued, J.-M., et al.: First multispacecraft ion measurements in and near the Earth's magnetosphere with the identical Cluster ion spectrometry (CIS) experiment, Ann.
Geophysicae, 19, 1303-1354, 2001.

Rodger, A. S. and Pinnock, M.: The ionospheric response to flux transfer events: the first few minutes, Ann. Geophysicae, 15, 685-691, 1997.

Rosenbauer, H., Grünwaldt, H., Montgomery, M. D., Paschmann, G., and Sckopke, N.: Heos 2 plasma observations in the distant polar magnetosphere: the plasma mantle, J. Geophys. Res., 80, 2723-2737, 1975.

Ruohoniemi, J. M. and Greenwald, R. A.: Statistical patterns of high-latitude convection obtained from Goose Bay HF radar observations, J. Geophys. Res., 101, 21 746-21 763, 1996.

Ruohoniemi, J. M. and Baker, K. B.: Large-scale imaging of highlatitude convection with Super Dual Auroral Radar Network HF radar observations, J. Geophys. Res., 103, 20 797-20 811, 1998.

Russell, C. T. and Elphic, R. C.: Initial ISEE magnetometer results: magnetopause observations, Space Sci. Rev., 22, 681-715, 1978.

Russell, C. T. and Elphic, R. C.: ISEE observations of flux transfer events at the dayside magnetopause, Geophys. Res. Lett., 6, 33 36, 1979.

Sandholt, P. E., Lockwood, M., Denig, W. F., and Leont'ev, S.: Dynamical aurora structure in the vicinity of the polar cusp - Multipoint observations during southward and northward IMF, Ann. Geophysicae, 10, 483-497, 1992.

Spreiter J. R. and Stahara, S. S.: A new predictive model for determining solar wind-terrestrial planet interactions, J. Geophys. Res., 85, 6769-6777, 1980.

Southwood, D. J.: The ionospheric signature of flux transfer events, J. Geophys. Res., 92, 3207-3213, 1987.

Taguchi, S. and Hoffman, R. A.: Ionospheric convection in the midnight sector for northward interplanetary magnetic field, J. Geomag. Geoelectr., 48, 925-933, 1996.

Thorolfsson A., Cerisier, J.-C., Lockwood, M., Sandholt, P. E., Senior, C., and Lester, M.: Simultaneous optical and radar signatures of poleward-moving auroral forms, Ann. Geophysicae, 18, 1054-1066, 2000.

Tsyganenko, N. A.: Modelling the Earth's magnetospheric magnetic field confined within a realistic magnetopause, J. Geophys. Res., 100, 5599-5612, 1995.

Vontrat-Reberac, A., Bosqued, J.-M., Taylor, M. G. G. T., Fontaine, D., Dunlop, M. W., Laakso, H., Cornilleau-Werhlin, N., Canu, P., and Fazakerley, A.: Cluster observations of the high-altitude cusp for northward interplanetary magnetic field: a case study, J. Geophys. Res., in press, 2003.

Wild, J. A., Cowley, S. W. H., Davies, J. A., Khan, H., Milan, S. E., Provan, G., Yeoman, T. K., Balogh, A., Dunlop, M. W., Fornaçon, K.-H., and Georgescu, E.: First simultaneous observations of flux transfer events at the high-latitude magnetopause by the Cluster spacecraft and pulsed radar signatures in the conjugate ionosphere by the CUTLASS and EISCAT radars, Ann. Geophysicae, 19, 1491-1508, 2001. 